\title{
UNCOVERING RELATIONS BETWEEN LEADERSHIP PERCEPTIONS AND MOTIVATION UNDER DIFFERENT ORGANIZATIONAL CONTEXTS: A MULTILEVEL CROSS-LAGGED ANALYSIS
}

\author{
Marylène Gagné \\ Curtin University \\ Alexandre J. S. Morin \\ Concordia University \\ Kira Schabram \\ University of Washington \\ Zhe Ni Wang \\ Southern Connecticut State University \\ Emanuela Chemolli \\ Chemolli Consulting \\ Mélanie Briand \\ Concordia University
}

\begin{abstract}
Marylène Gagné, Future of Work Institute, Curtin University, Australia; Alexandre J. S. Morin, Department of Psychology, Concordia University, Canada; Kira Schabram, Foster School of Business, University of Washington, Washington; Zhe Ni Wang, School of Business, Southern Connecticut State University, Connecticut; Emanuela Chemolli, Chemolli Consulting, Italy; Mélanie Briand, John Molson School of Business, Concordia University, Canada.

This research was supported in part by grants from the Social Sciences and Humanities Research Council of Canada, the Fonds Québécois de Recherche sur la Société et la Culture, and the Society for Human Resource Management awarded to the first author, by a grant from the Australian Research Council (LP140100100) awarded to the second author, and doctoral awards from Social Sciences and Humanities Research Council of Canada and the Fonds Québécois de Recherche sur la Société et la Culture granted to the fourth author. We wish to thank Ramon Rico for a friendly review. Correspondence concerning this article should be addressed to Marylène Gagné, Future of Work Institute, Curtin University, GPO Box U1987, Perth, Western Australia, 6845, Australia. Email: Marylene.gagne@.curtin.edu.au.
\end{abstract}

This is the accepted pre-publication version of the following publication:

Gagné, M., Morin, A. J. S., Schabram. K., Wang, Z. N., Chemolli, E., \& Briand, M. (in press). Uncovering relations between leadership perceptions and motivation under different organizational contexts: A multilevel cross-lagged analysis. Journal of Business and Psychology. Doi: 10.1007/s10869019-09649-4 


\begin{abstract}
Surprisingly scant research has adequately examined directional influences between different perceptions of managerial leadership behaviors and different types of work motivation, and even fewer studies have examined contextual moderators of these influences. The present study investigated longitudinal and multilevel autoregressive cross-lagged relations between perceptions of transformational, transactional, and passive-avoidant leadership with autonomous motivation, controlled motivation, and amotivation. Multilevel longitudinal models were estimated on data from 788 employees, nested under 108 distinct supervisors, from six Canadian organizations. Results revealed that perceptions of leadership behaviors predicted changes in motivation mostly at the collective level, and that some of these relations changed as a function of whether organizations had recently faced a crisis. Collective perceptions of transformational leadership were related to increased collective autonomous and controlled motivation, while individual controlled motivation was related to increased individual perceptions of transactional leadership. In organizations facing a crisis, individual perceptions of transactional leadership were related to decreased individual controlled motivation, while collective perceptions of transactional leadership were related to increased collective autonomous motivation, and decreased collective amotivation. In organizations not facing a crisis, collective perceptions of transactional leadership were related to decreased collective autonomous motivation. Implications for theory and practice are discussed.
\end{abstract}

Keywords: transformational leadership; transactional leadership; autonomous motivation; multilevel modeling 


\section{Uncovering relations between leadership perceptions and motivation under different organizational contexts: A multilevel cross-lagged analysis}

Over the past three decades, leadership research has been abundant and focused in great part on transactional and transformational leadership (Day, 2014). This research generally shows that transformational leadership (TFL, defined as leading through inspiration; Bass, 1985) leads to better outcomes than transactional leadership (TSL, defined as leading through exchange; Bass, 1985) or laissez-faire leadership (defined as a lack of leadership behavior; Bass, 1985; DeGroot, Kiker \& Cross, 2000; Lowe, Kroeck, \& Sivasubramaniam, 1996). Some of that research has explored how employee perceptions of managerial leadership behaviors relate to their motivational orientations. In particular, this research has shown that TFL seems to relate more to autonomous motivational orientations (i.e., motivation through interest and meaning; Deci \& Ryan, 1985), while TSL seems to relate more to controlled motivational orientations (i.e., motivation through rewards, sanctions, and ego-involvement; Deci \& Ryan, 1985; e.g., Bono \& Judge, 2003; Breevaart et al., 2014; Eyal \& Roth, 2011; Wang \& Gagné, 2013).

However, conclusions drawn out of this research may be inaccurate because of widespread reliance on cross-sectional designs that cannot adequately evaluate the directionality of associations between leadership perceptions and outcomes. In addition, past research has not considered the relative influence of multiple forms of leadership perceptions on multiple motivational orientations. Moreover, though leadership has been described as an inherently multilevel phenomenon, operating at both the individual and collective levels (Chun, Yammarino, Dionne, Sosik, \& Moon, 2009), little research to date has examined the location of leadership effects on work motivation. These design limitations can lead researchers and professionals to use results that are not substantively meaningful to develop theory and interventions, consequently limiting their validity and usefulness. Therefore, the present research examined relations between all forms of leadership from the full range model of 
leadership and all motivational orientations from self-determination theory (Bass, 1985; Deci \& Ryan, 1985), using autoregressive cross-lagged multilevel modeling that can provide more accurate information about the location (individual or collective) and direction of effects between leadership and motivation (Morin et al., 2014).

Finally, little research has considered how the organizational context might influence relations between leadership perceptions and motivation. We focused on organizational crises, defined as low probability high-impact events that threaten the viability of an organization (Pearson \& Clair, 1998), and how they might influence the type of leadership needed to foster and maintain employee motivation during such events, again using self-determination theory to explain the motivational mechanisms behind perceptions of managerial leadership behaviors. We empirically tested these ideas through moderation analyses embedded within the autoregressive cross-lagged multilevel models.

The present study brings a substantive-methodological contribution by examining relations between leadership perceptions and motivation, taking into consideration the direction of these associations, whether they are located at the individual or collective level, and the moderating role of the presence of organizational crisis on these relations. Such a research design can help identify core associations between leadership perceptions and motivation, and specify how organizational crisis may influence these core associations. This helps refine theory by refocusing it on essential elements, and orient future research on critical elements most likely to yield impactful interventions. After covering the literature on leadership as it relates to motivation, we elaborate on methodological issues and solutions to offer the most rigorous tests of the hypotheses using survey data, and present a study to test these hypotheses using these methodological solutions.

\section{The Full Range Model of Leadership}

Bass (1985) defined TFL as the extent to which a manager influences followers to feel 
trust, respect and loyalty, which in turn motivates them to work harder. In contrast, TSL represents the extent to which a manager promote compliance through rewards and punishments. Finally, laissez-faire leadership is characterized by a lack of involvement on the part of the manager and by the avoidance of the leadership role. TFL is composed of five interrelated elements: (1) attributed idealized influence, defined as perceptions of the manager as someone to be respected and admired; (2) behavioral idealized influence, defined as articulating values and behaving ethically; (3) inspirational motivation, defined as providing meaning and challenge to followers through a vision and enthusiasm; (4) individualized consideration, defined as paying attention to individual needs, coaching and mentoring; and (5) intellectual stimulation, defined as encouraging creativity and innovation (Bass \& Avolio, 1994). TSL theoretically includes contingent reward, defined as providing clear directives and giving out rewards and support in exchange for efforts; active management by exception, defined as monitoring deviances from standards and taking corrective action; and passive management by exception, defined as reacting only when things go wrong. Finally, laissez-faire leadership is the avoidance of leadership-like actions (Bass \& Riggio, 2006).

Although contingent reward was initially assumed to be a component of TSL, factorial and predictive evidence based on employees' ratings of their manager's behaviors shows that contingent reward perceptions are more closely related to TFL perceptions than to other transactional components, with correlations often above .70 (Antonakis, Avolio, \& Sivasubramaniam, 2003; Avolio, Bass, \& Jung, 1999; Bass \& Riggio, 2006; Heinitz, Liepmann, \& Felfe, 2005; Rafferty \& Griffin, 2004; Tejeda et al., 2001; Yukl 1999). This may be because of the way it is operationalized in the Multifactor Leadership Questionnaire (MLQ; Bass \& Avolio, 1995) through a focus on non-material rewards (e.g., assistance and positive feedback). Recognition, praise, and support have been shown to satisfy psychological needs, as will be explained in more detail later (Deci, Koestner, \& Ryan, 1999). Avolio and colleagues (1999) 
also argue that both TFL and contingent reward are "active and constructive forms of leadership" (p. 455), compared to other forms of TSL and laissez-faire leadership. This may explain why contingent reward perceptions, as assessed by the MLQ, tends to cluster with TFL perceptions (e.g., Heinitz et al., 2005).

Research has also shown that passive management by exception perceptions relates more strongly to laissez-faire leadership perceptions than to TSL perceptions (Avolio et al., 1999; Den Hartog, Van Muijen, \& Koopman, 1997; Heinitz et al., 2005), forming a "passive-avoidant leadership" (PAL) dimension. Thus, following this previous work on the factor structure of the MLQ, we conceptualized leadership perceptions as (i) TFL: all TFL components and contingent reward, (ii) TSL: active management by exception, and (iii) PAL: passive management by exception and laissez-faire leadership.

\section{Self-Determination Theory}

Self-determination theory (SDT; Deci \& Ryan, 1985) proposes a multidimensional conceptualization of motivation that includes autonomous motivation, defined as doing an activity out of meaning and/or interest, and controlled motivation, defined as doing an activity out of ego-involvement and/or external rewards and punishments. Amotivation represents a lack of any reason to engage in an activity. A large body of research shows that being autonomously motivated leads to better performance and wellbeing than controlled forms of motivation or amotivation (Deci \& Ryan, 2008). In the work domain, autonomous motivation has been related to increases in effort, acceptance of change, affective organizational commitment, physical and psychological wellbeing, and decreases in turnover (Gagné, 2014). Therefore, we can expect that motivation represents an important mechanism through which leadership influences these important work outcomes (Gagné \& Deci, 2005).

According to SDT, the psychological needs for autonomy, competence, and relatedness act as a gateway to autonomous motivation (Deci \& Ryan 2000). Contextual organizational 
factors that facilitate the satisfaction of these needs enhance autonomous motivation as well as a host of other positive employee outcomes (Van den Broeck et al., 2016). Among these contextual factors, autonomy supportive interpersonal behaviors can fulfill psychological needs, and thereby increase autonomous motivation. These behaviors include providing meaningful rationales for goals and action, acknowledging feelings, giving choice on how to do tasks, encouraging personal initiation, conveying confidence in subordinates' abilities, and providing positive feedback (Deci et al., 1999; Deci, Ryan, Gagné, Leone, Usunov, \& Kornazheva, 2001; Gagné, Koestner, \& Zuckerman, 2000). These autonomy supportive behaviors have not only been related to autonomous motivation, but also to engagement, wellbeing, and lower turnover (see Slemp, Kern, \& Ryan, 2018, for a meta-analysis).

\section{Relations between Leadership Perceptions and Motivation}

There is clear overlap between the leadership behaviors and the autonomy supportive behaviors described above. For example, inspirational motivation (providing a vision) is similar to providing a rationale, while individual consideration is akin to acknowledging feelings. Similarly, intellectual stimulation overlaps with encouraging initiative, while contingent reward leadership is similar to providing feedback. In other words, TFL behaviors are likely to enhance need satisfaction (and by association, motivation), something that has been argued in the leadership literature. For example, Conger (1999) argued that transformational managers affect their employees in three ways: (1) they increase followers' awareness of specific goals and (2) induce them to act beyond self-interest in the pursuit of these goals, all the while (3) satisfying followers' needs. Shamir, House and Arthur (1993) suggested that TFL involves increasing people's self-efficacy and self-worth, feelings of belongingness to a group and a cause, and the attribution of personal meaning to collective goals. Similarly, Bass and Riggio (2006) argued that TFL yields performance beyond expectations through increasing follower self-efficacy, identification with the leader, and goal and value alignment. Consistent with these views, there 
is also empirical support for the idea that the effects of TFL perceptions on employee motivation and outcomes involve the satisfaction of the needs for autonomy, competence, and relatedness (Hetland et al., 2011; Kovajnic et al., 2012, 2013).

Empirical evidence from research conducted at the individual level shows that TFL perceptions are positively related to autonomous motivation (Bono \& Judge, 2003; Charbonneau et al., 2001; Eyal \& Roth, 2011; Fernet, Trépanier, Austin, Gagné, \& Forest, 2015; Wang \& Gagné, 2013). Two diary studies also demonstrated that work engagement, which is closely related to autonomous motivation (Meyer \& Gagné, 2008), increases on days when managers show more TFL (Breevaart et al., 2014; Tims, Bakker, \& Xanthopoulou, 2011). In contrast, TSL perceptions are likely to promote more controlled forms of motivation, as it focuses on sanctioning followers, which may make employees feel pressured, infantilized, underchallenged, and unable to thrive. We thus argue that TSL perceptions (especially when defined in terms of management by exception as in the present study) are likely to increase controlled motivation but also possibly decrease autonomous motivation. Cross-sectional research at the individual level generally supports this assertion (Eyal \& Roth, 2011; Reeve \& Jang, 2006; Sarros, Tanewski, Winter, Santora, \& Densten, 2002). Finally, employees' perceptions of PAL are likely to make them feel unsupported and under-resourced, misguided, burdened, and anxious. These feelings are often associated with helplessness, which would be associated with a loss of motivation (Deci \& Ryan, 1985), and thus an increase in amotivation. As we could not locate any research examining relations between PAL perceptions and work motivation, the present study included this examination.

\section{Individual and Collective Leadership Perceptions and Motivation}

Most research has measured leadership either by asking managers to rate themselves, or by asking followers to rate their managers. Our research falls in the second category by focusing on perceptions that followers have of their leader. Research of this type needs to take into 
consideration data collected from multiple followers of the same leaders, which constitutes a shared variance component that needs to be explicitly taken into account. Beyond considering this statistical issue, leadership has been described as an inherently multilevel phenomenon, operating at both the individual and collective levels (Chun et al., 2009). At the collective level, a manager may behave in a manner that is consistent across subordinates, may enact leadership behaviors directly aimed at the collective (e.g., in a meeting), and may behave in a publicly visible manner toward individual followers. All of these behaviors form the substrate for the development of a leadership "climate" emerging from leadership perceptions that are shared among all followers (Joyce \& Slocum, 1984; Morin et al., 2014). It is also possible for a manager to act idiosyncratically towards specific subordinates in a way that is not always witnessed by, or shared with, other followers. These behaviors may lead employees working under a common manager to develop their own unique leadership perceptions, which may, or not, deviate from the shared leadership climate collective perceptions. Indeed, discrete leadermember exchanges have been shown to influence performance at the dyadic level (i.e., manager-subordinate pairs; Markham, Yammarino, Murry, \& Palanski, 2010).

So far, the majority of studies that have examined collective perceptions of leadership have aggregated (calculated a mean) leadership ratings at the collective level (Avolio, Zhu, Koh, \& Bhatia, 2004; Braun, Peus, Weisweiler, \& Frey, 2013; Charbonnier-Voirin, El Akremi, \& Vandenberghe, 2010; Chen et al., 2013; DeCelles, Tesluk, \& Taxman, 2013; Liao \& Chuang, 2007; Wang \& Howell, 2012; for an exception see Hoffman et al., 2011). This approach does not control for sampling error (i.e., within group variability in ratings of the collective construct; the non-collective part of the perceptions), which may not only result in biased parameter estimates (Lüdtke et al., 2008; Lüdtke, Marsh, Robitzsch, \& Trautwein, 2011; Marsh et al., 2010), but may also inaccurately represent an agreed-upon “climate”. Latent multilevel modeling approaches can be used to disentangle "climate" effects from idiosyncratic ones, 
which could help understand how TFL perceptions operate at both levels (Kozlowski, Mak, \& Chao, 2016). Doing so pools together common perceptions of a manager's leadership behaviors, and leaves idiosyncratic perceptions (i.e., deviations) at the individual level. It also offers a superior conceptualization of collective constructs representing the convergence of perceptions across individuals (Fulmer \& Ostroff, 2016). Little research has properly disaggregated the relations between leadership behaviors and work outcomes occurring at the individual and collective levels, which could lead to weaker effect sizes and to altogether different results (Marsh et al., 2012; Morin et al., 2014).

Although some studies have used multilevel analyses to examine cross-sectional relations between collective perceptions of TFL and group effectiveness (Avolio \& Yammarino, 1990; Wofford et al., 2001; Yammarino \& Bass, 1990), very few have examined motivation, and have done so while only considering some facets of motivation (i.e., intrinsic motivation or psychological empowerment) operationalized at the individual level (Avolio et al., 2004; Chen et al., 2013; Wang \& Howell, 2012). To our knowledge, no study has yet attempted to partition individual and collective levels of motivation, despite calls for research on collective motivation (Mathieu et al., 2017), which is proposed to be a potentially important source of dynamic capability in organizations (Barrick, Thurgood, Smith, \& Courtright, 2015; Gagné, 2018).

Conceptualizing work motivation at the collective level is not about a shared perception of a common referent that creates a "climate", as when subordinates assess a manager's leadership behaviors. Rather, collective motivation reflects a convergence of motivational orientations between group members (Fulmer \& Ostroff, 2016), which may emerge as a function of shared perceptions of leadership behaviors and ensuing group dynamics triggered by such perceptions (Kozlowski, 2012). If shared environmental factors, such as leadership climate, foster autonomous motivation, it is likely that subordinates working together and exposed to these same factors will show some level of convergence in their levels of autonomous motivation 
(Fulmer \& Ostroff, 2016). It is also possible for this leadership climate to trigger interactions between subordinates that would satisfy or frustrate their psychological needs, in turn fostering the convergence of motivation within groups. Therefore, we assume both direct and indirect mechanisms by which collective leadership perceptions may lead to collective motivation.

So far, only a handful of cross-sectional studies (Avolio et al., 2004; Chen et al., 2013; Hoffman et al., 2011; Wang \& Howell, 2012) have examined multilevel relations between leadership perceptions and motivation. Operationalizations of leadership climate vary across these studies, ranging from aggregates of individual perceptions of TFL to measures of groupfocused versus individual-focused TFL perceptions. All of these studies used a manifest aggregation process to create collective variables (i.e., averaging individual ratings), which fails to control for sampling error (operationalized as interrater disagreement; Bliese, Maltarich, \& Hendricks, 2018; Marsh et al., 2009, 2012; Morin et al., 2014). We are aware of one study by Hoffman et al. (2011) that used multilevel SEM to examine cross-sectional relations between employee TFL perceptions and group effectiveness. We took this approach in the current study.

Based on past cross-sectional multilevel research on TFL perceptions, which has found stronger effects at the collective rather than individual level (Chen et al., 2013; DeGroot et al., 2000; Wang \& Howell, 2012), we assume that the following hypotheses will be more strongly supported at the collective than at the individual level. However, we expect relations at both levels to be in the same direction (parallel effects).

Hypothesis 1 (H1). Higher perceptions of TFL lead to (a) increases in autonomous motivation, (b) decreases in controlled motivation, and (c) decreases in amotivation. Hypothesis 2 (H2). Higher perceptions of TSL lead to (a) decreases in autonomous motivation, and (b) increases in controlled motivation. Hypothesis 3 (H3). Higher perceptions of PAL lead to (a) decreases in autonomous motivation, (b) decreases in controlled motivation, and (c) increases in amotivation. 


\section{Directionality of Associations between Leadership Perceptions and Motivation}

Although theory and research leads us to expect that leadership perceptions will influence employee motivation, it is also plausible that employee motivation leads to changes in managerial behaviors over time, as managers seek to adapt their leadership style to the characteristics of their employees. It has indeed been demonstrated in laboratory and field studies that managers and teachers who believe, or are led to believe, that their followers are intrinsically motivated act in more supportive ways, whereas managers who are led to believe that their followers are extrinsically motivated act in more controlling ways (Pelletier \& Vallerand, 1996; Sarrazin, Tessier, Pelletier, Trouilloud, \& Chanal, 2006). In turn, these leadership behaviors may influence subsequent levels of motivation among followers, thereby confirming the need for this leadership style. Employee motivation might also influence their leadership perceptions (Wofford et al., 2001), which can be controlled through cross-sectional relations between leadership and work motivation when testing for the effects of leadership perceptions on motivation. Therefore, in order to ascertain that our hypotheses take into account these possible reverse relations, we controlled for them with fully cross-lagged analyses.

\section{Contextual Moderation of Leadership-Motivation Relations}

The last objective of this study was serendipitously made possible by significant events that happened in some of the participating organizations during the study. Each of these events corresponded to the definition of a crisis, which is generally taken to reflect "a low probability high-impact event that threatens the viability of the organization and is characterized by ambiguity of cause, effect, and means of resolution, as well as by a belief that decisions must be made swiftly" (Pearson \& Clair, 1998, p. 60). Likewise, Morgeson, Mitchell, and Liu (2015) characterized crises as “discrete, discontinuous 'happenings,' which diverge from the stable and routine features of the organizational environment" (p. 519), and can emerge inside or outside the organization. Morgeson et al. specified that a crisis' strength is determined by its novelty 
(different and unexpected), disruptiveness (creating confusion and uncertainty), and critical nature (requiring immediate attention and action). These unique circumstances provided us with a rare opportunity to assess how the associations identified between leadership perceptions and motivation occurring at the individual and group levels would be moderated by characteristics of the larger organizational context (i.e., here defined as being exposed or not to a crisis). However, because these events were not planned, we treat these analyses as exploratory.

Because crises can have debilitating effects on task processes and social relations in organizations, people may rely on their managers to cope with such disruptions (Kahn, Barton, \& Fellows, 2013). Research to date has mostly focused on crisis as a determinant of TFL perceptions (Hunt, Boal, \& Dodge, 1999; Williams, Pillai, Deptula, \& Lowe, 2012), or on how managers understand crises and adapt their behaviors (Mumford, Friedrich, Caughron, \& Byrne, 2007). One study examined how environmental uncertainty moderated relations between leadership perceptions and firm performance, and found that TFL was only positively related to firm performance under environmental uncertainty, while TSL was never related to the outcome (Waldman, Ramirez, House, \& Puranam, 2001). The present study similarly explored whether organizational crisis moderates relations between leadership perceptions and work motivation, but using a much bigger sample and latent aggregation methods.

Bass and Riggio (2006) argued that TFL is particularly useful to cope with stress and change, and help foster followers' development. This may be because followers feel a loss of control and increased levels of stress during a crisis, which makes them more vulnerable to the influence tactics of a transformational manager who may offer solutions (Bligh \& Kohles, 2009; Mumford et al., 2007; Waldman \& Yammarino, 1999; Williams et al., 2012). TFL perceptions have been shown to be particularly important in stressful work environments, such as during major organizational change. Studying a large merger process, Nemanich and Keller (2007) found a positive relation between TFL perceptions, job satisfaction, and merger acceptance 
among employees. Gooty, Gavin, Johnson, Frazier, and Snow (2009) showed that followers' perceptions of a newly introduced director's TFL were positively related to their in-role performance and organizational citizenship behaviors. These findings suggest that TFL perceptions may help employees find meaning behind the change (Weick, 1995), which could help preserve or increase autonomous work motivation in a time of crisis. TFL perceptions could also help protect employees against increases in controlled motivation and amotivation during times of crisis. However, other studies suggest that exposure to a crisis could decrease TFL perceptions, as it could signal ineffective leadership (Pillai \& Meindl, 1998).

There are also arguments for the value of TSL during a crisis. Indeed, because crises often involve the need for swift decision-making from managers (Mumford et al., 2007), direction and focus may be particularly sought out by followers (Yukl, 2002). House's (1971) path-goal theory of leadership specifies that a directive style is more effective in times of crisis than a participative style. Hunt et al. (1999) argue that "crisis-responsive charisma" involves acting first, and providing a vision for this action later. Followers have been shown to prefer directive, authoritarian leadership in emergencies and crises (Mulder, Ritsema van Eck, de Jong, 1971; Mulder, de Jong, Koppelar, \& Verhage, 1986), and when facing internal conflict (Katz, 1977). As such, it may be that a focus on getting things done may make followers feel more secure in times of crisis thereby promoting autonomous motivation, and perhaps decreasing levels of controlled motivation and amotivation. Indeed, providing direction and close monitoring may help keep followers focused on what needs to be done to "survive". Keeping things tight may also keep followers together and increase their sense of cohesion, while staying focused on a narrow goal during a crisis may restore some of the lost meaning experienced by followers. A study where members of rural Israeli settlements were asked about their leadership preferences in routine and crisis times (Boehm, Enoshm, \& Michal, 2010) concluded that members expected higher levels of both TFL and TSL in times of crisis. Another series of studies demonstrated that 
promotion-focused communications (compatible with TFL) promoted greater effort on tasks (indicating more motivation) and better performance than prevention-focused communications (compatible with TSL) in times of crisis but there was no difference when there was no crisis (Stam, van Knippenberg, Wisse, \& Nederveen Pieterse, 2018).

Because of the serendipitous aspect of the crisis variable in the present study, combined with the divided views on the role of TFL and TSL in times of crisis, we test the following research question.

Research Question: Will the presence of an organizational crisis change the strength or direction of relations between perceptions of leadership and work motivation?

\section{Study Overview: A Longitudinal Autoregressive Cross Lagged Multilevel Approach}

The present research investigated cross-lagged relations between leadership perceptions and types of motivation at the individual and collective levels using latent aggregation methods. It included perceptions of all forms of leadership behaviors from the full range leadership model, and all forms of motivation encompassed by SDT to assess the relative contribution of each facet of followers' leadership perceptions in the prediction of each type of motivation. It included two assessments of leadership and motivation with a one-year time lag, which made possible the examination of the directionality of relations between leadership behaviors and motivation types. These features help avoid many of the threats to validity that have plagued leadership research (Antonakis et al., 2014).

\section{Method}

\section{Sample and Procedure}

Eight hundred and fifty-six full-time employees from six Canadian organizations participated in a study on leadership and motivation. In each organization, we coded which manager each employee rated. We retained a final sample of 788 participants $(92.06 \%)$, based on having a minimum of three employees reporting on each manager. They had a mean age of 
44.40 years $(S D=10.25)$ and a mean organizational tenure of 3.21 years $(S D=1.32)$. Of them, $66.9 \%$ were males and $33.1 \%$ were females. These 788 employees provided ratings for 108 managers, each of which was rated by an average of 7.30 employees (ranging from 3 to 31 ).

Two identical surveys were administered 6 to 18 months apart, and participation was voluntary and confidential. Among participants, 709 completed all scales at Time 1 and 611 completed all scales at Time 2 (with 471 completing both times and 856 completing at least one wave of data). Surveys were completed online or on paper (administered on-site by the researchers, with the option to opt-out by submitting a blank survey in a sealed envelope), depending on whether employees used company email in their work.

Organizational Characteristics and Crisis Categorization. We categorized the six participating organizations as experiencing a crisis or not by evaluating whether they experienced a low probability high impact event that posed a threat to the organization's core functioning between Time 1 and Time 2 (Pearson \& Clair, 1998). Using Morgeson et al.'s (2015) criteria, we evaluated if events and their consequences, either observed by the researchers or reported by the organization during the course of the study, were novel (unexpected), disruptive (creating confusion and uncertainty that affected functioning and effectiveness), and critical (requiring immediate attention and action). Classification was done independently by the first two authors, using information obtained while conducting research in each of the organizations. Convergence in their ratings of the crisis situation was $100 \%$. It was indeed the case that organizations classified as "in crisis" experienced at least one major event during the study period that met the three criteria described above.

The first organization ( $n=133$ ) was a software development company. Data collections happened in April 2008 and June 2009. In between the two assessments, an economic crisis (unexpected) hit the company, and before the T2 data collection, the company drastically restructured and downsized in an attempt to survive this crisis (disruptive and critical). For this 
reason, it was categorized as "in crisis". The second organization $(n=141)$ was a government organization that did not experience any novel, disruptive, and critical event during the course of the study, and was thus characterized as "not in crisis". The data collections happened in December 2009 and December 2010. The third organization $(n=192)$ was another government organization where data collections happened in October 2010 and April 2011. The general director (which was appointed by the government) quit in December 2010 following news that one of their major projects, on which a large group of employees had been working for the last two years, which would have changed the work of all employees in the organization had it gone ahead, and which had required a major investment of time and resources for the last several years, was unexpectedly cancelled by the government. These events led to the appointment of an interim director and restructuring that not only affected the work of the majority of employees in this organization, but also caused high levels of demoralization amongst this workforce (disruptive and critical). As such, it was categorized as "in crisis".

The next organizations were branches of the same multinational manufacturing company operating autonomously in distinct Canadian provinces. In the first branch $(n=205)$, data collection occurred in October 2009 and April 2011. It experienced an important financial downturn, coupled with conflictual collective bargaining (industrial actions and lock out: unexpected and disruptive) that led to its demise in early 2013 (critical). It was thus categorized as "in crisis". Data collections were done in November 2010 and November 2011 in the second branch $(n=70)$, and November 2010 and January 2012 in the third branch $(n=47)$. No major event threatened these branches, which were categorized as "not in crisis".

\section{Measures}

Leadership Perceptions. Subordinates completed 36 items from the Multifactor Leadership Questionnaire (MLQ) Form $5 \mathrm{x}^{1}$ using a 0 (not at all) to 4 (frequently if not always) Likert scale (Bass \& Avolio, 1995), which includes the following 4-item subscales: (1) 
attributed idealized influence; (2) behavioral idealized influence; (3) inspirational motivation; (4) intellectual stimulation; (5) individualized consideration; (6) contingent reward; (7) active management by exception; (8) passive management by exception; and (9) laissez-faire leadership. Following Avolio et al. (1999) and Heinitz et al. (2005), items from subscales 1 to 6 were grouped to assess an overarching TFL construct, items from subscale 7 were used to assess TSL, and items from subscales 8 and 9 were grouped to assess PAL.

Work Motivation. Subordinates completed the 19 items from the Multidimensional Work Motivation Scale (Gagné et al., 2015). Participants were asked to describe why they put efforts into their job using a 1 (Not at all) to 7 (Completely) Likert scale on items reflecting: (1) amotivation (3 items; e.g., I don't, because I really feel that I'm wasting my time at work); (2) material external regulation (3 items; e.g., Because others will reward me financially only if I put enough effort into my job); (3) social external regulation (3 items; e.g., To get others' approval); (4) introjected regulation (4 items; e.g., Because otherwise I will feel ashamed of myself); (5) identified regulation (3 items; e.g., Because I personally consider it important to put effort into this job); and (6) intrinsic motivation (3 items; e.g., Because I have fun doing my job). Gagné et al. found support for the a priori factor structure of the instrument, and for a second-order structure including two higher-order factors of autonomous (subscales 5 and 6) and controlled (subscales 2 to 4) motivation, separated from an amotivation factor (subscale 1).

\section{Analyses}

Hypotheses were tested using autoregressive cross-lagged analyses (e.g., Jöreskog, 1979; Morin et al., 2011) at two levels (L1: individual and L2: collective) using multilevel latent aggregation (Morin et al., 2014). Such analyses allow for a clear investigation of the directionality of associations between the constructs by allowing for the simultaneous estimation of relations whereby each variable at the first time point is allowed to predict variables at the next time point (the cross-lagged component). These relations are also estimated while 
controlling for the longitudinal stability of each construct (the autoregressive component) so that results reflect the effects of each construct measured at the first time point on increases or decreases in other constructs relative to the baseline (Time 1) level (for illustrations of these models in the organizational area, see Boudrias, Morin, \& Lajoie, 2014; Morin et al., 2016).

Because of the complexity of the autoregressive cross-lagged multilevel models that form the essence of this study, attempts to estimate them using fully latent variable models (i.e. where each construct was assessed directly from the items in a latent variable framework in order to provide a more complete control for measurement errors present at the item level, see Marsh et al., 2009, 2012; Morin et al., 2014) failed to converge, or converged on improper solutions (e.g., negative variance estimates, non-positive definite matrix, etc.). In the statistics literature, nonconvergence is often taken to reflect overparameterized models (i.e., trying to estimate too much with the data) and the need to rely on more parsimonious models (e.g., Chen et al., 2001). Given the analytical complexity of doubly-latent multilevel models, nonconvergence is relatively common, as observed in Lüdtke et al.'s $(2008,2011)$ statistical simulations studies. In these cases, Lüdtke et al.’s $(2008,2011)$ results show that there are important advantages, both in terms of convergence but also in achieving unbiased estimation of model parameters with an adequate level of statistical power, associated with the adoption of simpler models based on manifest variables (rather than fully latent measurement models; Lüdtke et al., 2008, 2011). This is the approach taken in the present study (for more on the theoretical and practical underpinnings of latent multilevel approaches, see Morin et al., 2014, and Marsh et al., 2012).

We thus estimated models using factor scores saved from preliminary measurement models estimated while taking into account individuals' nesting within managers with the design-based correction of standard errors available in Mplus 7.2 (Asparouhov, 2005; Muthén \& Muthén, 2014). We started this study by estimating a series of measurement models designed to verify the adequacy of the a priori structure underlying the instruments used in this study, as 
well as their longitudinal measurement invariance across time points and type of organization (crisis versus no crisis; e.g., Meredith, 1993; Millsap, 2011). Although factor scores do not explicitly control for measurement error, they remain superior to scale scores in this regards by giving more weight to items with lower levels of measurement errors (i.e. those with the highest factor loadings, and thus lowest uniquenesses), providing a partial control for measurement errors. Another key advantage of using factor scores, in addition to providing an elegant way of handling missing data while taking into account all of the information present at the item level (Enders, 2010; Graham, 2009), is the ability to save them from a model of complete longitudinal invariance (Millsap, 2011), ensuring that the definition of the constructs remains unchanged over time. The full set of details regarding the specifications and estimation of these models are reported in the online supplements. These models achieved a satisfactory level of fit to the data, and were found to be completely invariant across time waves and organizations.

The factors scores saved from these preliminary models were then used in the estimation of the multilevel cross-lagged path analytic models used to test our hypotheses, relying on the robust Maximum Likelihood (MLR) estimator available in Mplus 7.2 (Muthén \& Muthén, 2014). In this model, leadership and motivation factors are modelled at the individual (L1) and collective (L2) levels. This model relied on a latent aggregation process to properly disaggregate the variance between L1 and L2 while controlling for the levels of inter-rater agreement (or sampling error, see Marsh et al., 2009, 2012; Morin et al., 2014) between employees nested under a single manager in the creation of the L2 constructs. Ensuring a minimum of three employees rating each manager helps meet a critical assumption of multilevel models to achieve proper disaggregation of L1 and L2 effects through latent aggregation (Lüdtke et al., 2008, 2011; Marsh et al., 2009, 2012; Morin et al., 2014). These models were all estimated while taking into account individuals' and managers' nesting within organizations using Mplus design-based correction of standard errors (Asparouhov, 2005; Muthén \& Muthén, 2014). 
Autoregressive paths were modelled within each family of variables (e.g., all motivation factors at T1 predict all motivation factors at T2), and cross-lagged paths between leadership and motivation factors were all integrated to the model. Autoregressive paths explicitly control for the stability of each construct over time. This model is fully saturated as is typically the case for autoregressive cross-lagged models based on manifest variables and two time points. This is also in line with typical application of multilevel path analytic models (based on manifest variables, or factor scores) where model fit is typically not reported, due in part to the high level of unreliability of model fit indicators of when applied to the multilevel framework - especially when applied to L2 (Hsu, 2009; Ryu \& West, 2009).

We finally tested whether crisis status would moderate individual and collective relations by conducting additional analyses using a three level (L1: Individual, L2: Manager; L3:

Organizations) multilevel random slopes analyses with crisis status as a level 3 moderator of the relations identified at L1 and L2. More precisely, regression slopes at L1 and L2 were specified as random and allowed to differ as a function of the crisis status variable located at L3.

\section{Results}

\section{Preliminary Verifications}

Latent variable correlations from the preliminary measurement models are reported in Table 1, together with estimates of scale score reliability, intraclass correlation coefficients, and correlations between the factor scores and follower demographic characteristics ${ }^{2}$. Supporting the adequacy of this model, scale score reliability coefficients for the latent factors all proved to be fully satisfactory according to McDonald's (1970) model-based omega $(\omega)$ coefficient (which is computed from the model standardized loadings and uniquenesses and thus directly reflects the strength of the factors). In this study, $\omega$ varied from .678 to $.968(\mathrm{M}=0.850)$. This satisfactory level of reliability suggests that the partial level of correction for measurement errors afforded by factor scores is likely to be sufficient. 
The intraclass correlation coefficient (ICC1) estimates the amount of variability present at L2. The ICC1 is calculated as $\frac{\tau_{x}^{2}}{\tau_{x}^{2}+\sigma_{x}^{2}}$, where $\tau_{x}^{2}$ is the L2 variance and $\sigma_{x}^{2}$ is the L1 variance, and should ideally be close to or higher than .1, but is seldom larger then .3 (Hedges \& Hedberg, 2007; Lüdtke et al., 2008, 2011). In this study, ICC1 values were all generally satisfactory (.060 to $.252 ; M=0.178$ ), albeit slightly lower for motivation constructs that are more naturally located at L1. This observation indicates that meaningful variability is indeed present at L2, thus reinforcing the importance of including both levels in the analyses.

Another important consideration in multilevel models is the level of agreement among employees in the rating of L2 constructs. This is typically assessed with the ICC2, which directly reflects the reliability of L2 aggregates and is calculated as $\frac{\tau_{x}^{2}}{\tau_{x}^{2}+\left(\sigma_{x}^{2} / n_{j}\right)}$ where $n_{j}$ is the average size of L2 units (Bliese, 2000; Raudenbush \& Bryk, 2002; Lüdtke et al., 2008, 2011). ICC2 values are interpreted in line with other reliability measures (e.g., Marsh et al., 2012), and in this study varied from the low to acceptable range $(.319$ to $.831 ; M=.575)$. The latent aggregation process implemented in this study is specifically designed to take into account this form of measurement error related to the level of agreement (or disagreement) between the different assessors of the L2 constructs. In other words, latent aggregation is particularly important when ICC2 values are in the low range such as in the present study.

Correlations between study variables are presented in Table 1. Although these correlations are calculated at the individual level, they are still informative. First, they show that all constructs present a relatively high level of temporal stability (i.e. test retest reliability) over the course of the study ( $r=.447$ to $.710, M=.605)$, reinforcing the need to control for autoregressive paths (allowing us to assess the effects of predictors over and above this longitudinal stability) in the main predictive models. Second, although these results show that cross-sectional associations among different constructs $(|r|=.008$ to $.616, M=.224)$ tend to be 
stronger than longitudinal correlations $(|r|=.005$ to $.407, M=.158)$, they also show that many longitudinal correlations remain significant (23 out of 36). These correlations support the discriminant validity (i.e., distinctiveness) of all constructs considered here, both within and across time points. Furthermore, these longitudinal correlations apparently go both ways, suggesting associations between Time 1 motivation constructs (particularly autonomous motivation) and Time 2 perceptions of leadership behaviors, but also between Time 1 perceptions of leadership behaviors (particularly TFL) and Time 2 motivation constructs.

\section{Autoregressive Cross-Lagged Multilevel Analyses}

Results from the multilevel autoregressive cross-lagged analysis are reported in Table 2. Autoregressive path results supported correlational results by showing that each construct proved to be quite stable over time at the employee level. At the collective level, leadership behaviors presented a high level of stability over time. However, collective motivations showed lower levels of temporal stability.

At the individual level, the predictive cross-lagged results showed that none of the leadership factors (reflecting deviations in individual ratings from the average rating of the manager provided by all employees) predicted increases or decreases in the motivational factors over time. Therefore $\mathrm{H} 1$ to $\mathrm{H} 3$ were not supported at the individual level. In contrast, individual levels of controlled motivation significantly and positively predicted increases in perceptions of TSL over time, showing that workers with more controlled motivation tended to perceive their manager as using increasing levels of TSL over time. However, this effect remained small and none of the other forms of motivation predicted changes in perceptions of leadership over time.

At the collective level, two effects were found, showing that collective perceptions of TFL positively predicted collective increases in controlled and autonomous motivation. Thus, shared perceptions of the manager's TFL were associated with increasing collective controlled and autonomous work motivation over time. The collective effect of TFL on autonomous motivation 
was slightly stronger than the effect on controlled motivation. Results also show that collective perceptions of TSL and PAL had no impact on employees' collective motivation. None of the collective motivational factors predicted increases or decreases in collective leadership factors. This supports H1a, and an effect contrary to that predicted in $\mathrm{H} 1 \mathrm{~b}$, but none of the other hypotheses at the collective level were supported.

\section{Exploring the Moderating Role of Organizational Crisis}

At the individual level, one relation was found to differ as a function of crisis status. More precisely, crisis status moderated the relation between individual differences in perceptions of TSL and variations in individual levels of controlled motivation over time $(b=-.073, S E=.030$, $p<.05)$. Simple slopes analyses indicated that in organizations in crisis, more pronounced perceptions of TSL predicted decreases in employee levels of controlled motivation over time ( $b$ $=-.050, S E=.015, p<.01)$, whereas this relation was non-significant in organizations not in crisis $(b=.023, S E=.027, p>.05)$.

At the collective level, two relations differed as a function of crisis. First, crisis moderated the relation between collective perceptions of TSL and variations in collective amotivation $(b=$ $-.161, S E=.075, p<.05)$. Simple slopes analyses indicated that in organizations in crisis, higher collective perceptions of TSL predicted decreases in collective amotivation over time $(b=-.150$, $S E=.066, p<.05)$. This relation was non-significant for organizations not in crisis $(b=.011, S E$ $=.048, p>.05)$. Second, crisis status moderated the relation between collective perceptions of TSL and variations in collective autonomous motivation $(b=.229, S E=.032, p<.01)$. Simple slopes analyses indicated that in organizations in crisis, higher collective perceptions of TSL predicted increases in collective autonomous motivation $(b=.101, S E=.023, p<.01)$. For organizations not in crisis, higher collective perceptions of TSL predicted decreases in collective autonomous motivation over time $(b=-.128, S E=.037, p<.01)$. This supports for H2a in that TSL leads to decreased autonomous motivation, but only in organizations not facing a crisis. 


\section{Discussion}

The present study set out to uncover key relations between leadership perceptions and motivation orientations occurring at the individual and collective levels by modeling multilevel autoregressive cross-lagged influences between all forms of leadership behaviors from the fullrange model of leadership and all types of motivation from self-determination theory. This allowed us to (1) examine the directionality of the relations between leadership perceptions and employee motivation, (2) examine these relations at both the individual and collective levels, (3) control for sampling error (i.e. inter-rater reliability) in the assessment of collective constructs through a process of latent aggregation; and (4) control for the longitudinal stability of the constructs in order to explicitly assess the impact of each variable on increases or decreases in the other variables over time (using auto-regressive paths). In addition, the study explored the influence of organizational crises to determine if the organizational context moderated relations between leadership perceptions and motivation. By using such a rigorous approach, this study helps uncover the strongest relations between leadership and motivation, which can help refine theory, focus future research, and develop impactful interventions.

As expected, more meaningful effects were found at the collective level than at the individual level. Indeed, no relations were identified between individual differences in followers' perceptions of leadership behaviors and their motivational orientations. At the collective level, perceptions of TFL (reflecting a leadership climate of TFL) increased autonomous work motivation. However, collective perceptions of TFL also increased collective levels of controlled work motivation and were unrelated to collective levels of amotivation. Collective perceptions of TSL did not influence changes in collective levels of motivation, and perceptions of PAL did not lead to increases in amotivation. Looking at the reverse effect of motivation on perceptions of leadership, we only found a small effect indicating that individual controlled motivation led to increases in individual perceptions of TSL. 
The presence of an organizational crisis context was also found to influence some relations between leadership perceptions and motivation. Our exploratory analyses did not reveal any differences related to relations involving TFL between the organizations in crisis and those not in crisis. Furthermore, although collective perceptions of TSL were generally not found to influence changes in collective levels of motivation, a few interesting effects emerged when we took into consideration the crisis status of the organizations. First, when organizations experienced a crisis, collective perceptions of TSL led to decreases in collective levels of amotivation and to increases in collective levels of autonomous motivation, while idiosyncratic perceptions of TSL led to decreases in individual controlled motivation. In contrast, in the absence of crisis, TSL perceptions were associated with a decrease in collective levels of autonomous motivation. These results differ from those reported in Waldman et al.'s (2001) study, where TFL perceptions were only related to organizational performance under environmental uncertainty, and where TSL perceptions were never found to be related with organizational performance no matter how uncertain the environment was. These differences could possibly be explained by the many methodological differences between this study and Waldman et al.'s (2001) who relied on a smaller sample size, shorter measures, and a lack of control for sampling error, while also considering a different outcome. However, the current results related to variations in the effects of TSL as a function of crisis support results from other previous studies showing that in times of crisis there may be good reasons to use TSL (Boehm et al., 2010; Mulder et al., 1971, 1986).

\section{Theoretical Implications}

We demonstrated through this study that using a more rigorous research design helps uncover critical directions of influence between perceptions of managerial leadership and work motivation, and helps refine the statement that leadership perceptions simultaneously have an individual and a collective component (Chun et al., 2009). Results concur with previous 
research showing that the effect of transformational leadership perceptions on motivation is mainly located at the collective level (Chen et al., 2013; Wang \& Howell, 2012), which contrasts with other research in which the effects of leadership perceptions on other outcomes have been located at the individual level (Avolio \& Yammarino, 1990; Yammarino \& Bass, 1990). These differences could be due to the use of more precise statistical techniques, an issue that we address in the next section. Substantially, our results imply that the use of transformational leadership behaviors seems to take effect over a collective rather than at the individual level. This is not surprising when many transformational leadership behaviors (e.g., role modeling, participative approach, articulating a vision) tend to be enacted publicly, though witnessing more individualized supportive behavior towards a colleague could also have spillover or vicarious effects on the rest of a unit.

In contrast, TSL influenced employee motivation only in crisis situations, and at both the individual and collective levels. These results provide support for contingency theories of leadership that advocate the use of leadership behaviors that are appropriate to the situation (e.g., House, 1971) rather than invariably using TFL and avoiding TSL as advocated in the full range model of leadership (Bass \& Riggio, 2006). Results indicated that it may be beneficial (for both individual and collective motivation) for managers to become more directive and focused on solving emerging problems (i.e., as reflected in ratings of TSL) during times of crisis. Organizational instability may create a need for clear procedures, structure, and guidance to reassure employees, in order to continue fulfilling their basic needs for competence and autonomy in a situation where these are challenged. It may also call for fulfilling their need for relatedness by keeping groups together through tough times. Moreover, such leadership behaviors may promote a different configuration of need supportive behaviors amongst subordinates to preserve need satisfaction. It would be very interesting to examine this in future research as these mechanisms could explain the decrease in collective amotivation and increase 
in collective autonomous motivation found in this study. The decrease in individual controlled motivation in organizations facing a crisis could suggest that individually tailored TSL may be more directly triggered by idiosyncratic needs in solving day-to-day difficulties during a crisis. Finally, when there was no crisis, collective perceptions of TSL decreased collective autonomous motivation, as we had expected, suggesting that TSL should only be used when it is needed to maintain psychological need satisfaction.

In addition, our results indicate that, once TFL and TSL are taken into consideration, PAL does not influence motivation. Both the full range model of leadership and self-determination theory predict that PAL should foster helplessness and a loss of meaning, but to our knowledge no empirical work has ever examined these propositions. This might mean that the inclusion of PAL may not be necessary to explain motivation, but it could still be necessary to explain other outcomes. One could also argue that including amotivation is unnecessary. However, research has demonstrated that amotivation does account for variance in outcomes beyond that accounted for by the other forms of motivation (e.g., Howard, Gagné, Morin, \& Van den Broeck, 2016).

With one exception, we found no reverse effects of collective and individual motivation on changes in perceptions of leadership, which may mean that at least in the context of our study, motivation does not influence leadership perceptions. The sole exception was a small effect of idiosyncratic levels of controlled motivation increasing perceptions of TSL. We speculate that employees who are particularly controlled in their motivation may end up attributing more monitoring-type behaviors to their managers due perhaps to a greater sensitivity to environmental controls (Deci \& Ryan, 1985). Alternatively, it is also possible that employees with higher levels of controlled motivation relative to their peers may act in a manner that leads their manager to act in a more controlling way with them than with other subordinates (Pelletier \& Vallerand, 1996; Sarrazin et al., 2006). Future studies could investigate this process by focusing on longitudinal employee-manager interactions. 


\section{Methodological Implications}

Though some research has looked at the relations between leadership perceptions and motivation, most of this research has not examined the relative contribution of the different types of leadership styles on motivation (Hinkin \& Schriesheim, 2008), has not considered the full range of motivational orientations proposed by SDT (Gagné \& Deci, 2005), has failed to consider the individual versus collective components of these associations, and has relied on cross-sectional or unidirectional longitudinal designs. This last limitation precludes an investigation of the directionality of these associations and makes it impossible to separate the effects of leadership perceptions on employee behaviors from the effects of employee behaviors on leadership perceptions. These design issues all constitute threats to the validity of research results (Antonakis et al., 2014). The consideration of multiple forms of leadership and motivation, allowing us to consider their relative contributions, and reliance on rigorous longitudinal multilevel analyses involving a latent aggregation process, constitute strengths of this study. Such a design provides more certainty as to which effects are important and worth considering when developing theory and interventions, and should be seriously considered in future research design.

More broadly, the analytical methods implemented in the present study provide a way to simultaneously address many of the key methodological considerations faced by organizational researchers. First, organizational researchers are typically interested in achieving a clearer understanding of the directionality, as a first step in the establishment of causality, of the associations between key constructs of interest. Although autoregressive cross-lagged analyses are not the only way to model longitudinal phenomena with greater precision, it does provide one way of establishing directionality. Interestingly, most of these other approaches can also be estimated within a latent multilevel framework and could be used interchangeably with the methods used in the present study to study change (McArdle, 2009), to investigate the shape of 
developmental trajectories and group variations in the shape of these trajectories (Grimm, Ram, \& Estabrook, 2017), to adopt a more dynamic perspective on momentary fluctuations (Asparouhov, Hamaker, \& Muthén, 2018), or finally to disaggregate our understanding of longitudinal relations into their respective state and trait components (Morin et al., 2011).

Second, organizational researchers study phenomena that occur simultaneously, and often differentially, at multiple levels of analyses: occasions, person, workgroup, branch, organization, country, etc. Multilevel approaches are required to properly disaggregate effects occurring at multiple levels of analyses. In particular, a key component of multilevel models is the need to adopt a proper specification of higher level (e.g., Level 2, collective) variables formed based on the aggregation of ratings obtained at the lower level (e.g., Level 1, individual) as the appropriate method for such aggregation procedures depends on the nature of the collective construct (Marsh et al., 2009, 2012; Morin et al., 2014). Level 2 climate constructs are formed on the basis of Level 1 ratings directly reflecting that Level 2 construct, such as when employees' were asked to rate their supervisors' leadership behaviors. Level 2 contextual constructs are rather formed on the basis of Level 1 ratings that make sense on their own, such as employees were asked to rate their motivation - leading to a Level 2 aggregate reflecting the motivational context of the workgroup.

Results of this study concur with previous research showing that the effect of leadership perceptions on motivation is mainly located at the collective level (Chen et al., 2013; Wang \& Howell, 2012), but also contrast with other research in which the effects of leadership perceptions on other outcomes have been located at the individual level (Avolio \& Yammarino, 1990; Yammarino \& Bass, 1990). In particular, although the inter-rater reliability of the collective aggregates of leadership perceptions was satisfactory, that of motivation ratings was marginal. This means that collective aggregates obtained without a latent aggregation process would directly introduce a substantial amount of inter-rater measurement error at the collective 
level, which decreases the likelihood of observing significant relations at this level.

Third, and perhaps more importantly, organizational research often relies on imprecise measurement procedures that are naturally tainted by some form of measurement error. The need to control for random measurement error in the estimation of relations among constructs has long been advocated as one key advantage of Structural Equation Models (SEM; Bollen, 1989). Yet, the complexity of longitudinal research, just like that of multilevel research, has long meant that researcher tend to limit their research efforts to controlling for one of these key confounders: directionality, level, or error. Yet, as we have shown in the present study, there is no need for these procedures to be mutually exclusive. Importantly, doubly-latent multilevel SEM models (Marsh et al., 2009, 2012; Morin et al., 2014) provide a way to estimate longitudinal models while controlling for two important sources of measurement errors present in multilevel ratings. Through the incorporation of latent variables specified within the SEM framework, these models are able to control for random measurement errors present at the level of item ratings. In addition, through the reliance on a latent aggregation process to form the Level 2 composite, they also provide a way to control for inter-rater reliability in the combination of Level 1 ratings. As was the case in the present study, it may not always be possible or desirable (Lütdke et al., 2008, 2011) to rely on both form of latent controls (i.e., on doubly latent models). Yet, even when these models failed, we demonstrated a way to achieve partial control for item-level random measurement error via factor scores, in combination with a complete latent aggregation process. Clearly, organizational researchers would do well to consider more thoroughly the possible benefits of this doubly latent multilevel longitudinal SEM framework for their own research.

\section{Limitations and Future Directions}

Despite its methodological strengths, this study also has limitations that need to be taken into account. First, although we relied on a rigorous cross-lagged analyses of temporally 
measured variables, we cannot draw definitive causal interpretations as this would require experimental designs involving variable manipulations (see Bono \& Judge, 2003 for an example). Second, though the use of subordinate reports of managerial leadership is considered a better alternative to asking managers to report on their own leadership behavior (Bass \& Avolio, 1994), especially when assessing the impact of leadership on subordinate outcomes, future research could use additional sources of information, such as observer reports and experimental manipulations of leadership behaviors. Without this, despite the ability to clearly disaggregate the effects from collective perceptions from the effects of idiosyncratic interindividual differences, it remains impossible to completely isolate the effects of true leadership behaviors from those of subordinate perceptions and outcomes.

Third, TFL components were not examined separately in the present study, not only because of difficulties in reaching convergence on proper solution in the context of complex statistical models such as those used in the present study, but also because of the added complexity of positing differential hypotheses for each TFL components on each type of motivation. It would be informative, as has been pointed out by van Knippenberg and Sitkin (2013), to understand the impact of specific TFL components on employee motivation, possibly by examining how these components influence the satisfaction of autonomy, competence, and relatedness. So far, research has only examined and found that overall TFL is related to the satisfaction of the three needs (Hetland et al., 2011; Kovajnic et al., 2012, 2013). In contrast, our research focused on the broader difference between TFL, TSL, and PAL perceptions in a multilevel longitudinal model, paving the way for future studies of TFL components.

Relatedly, it would be interesting to use a different conceptualization of contingent reward leadership that would enlarge its scope beyond the operationalization offered in the MLQ, which focuses mostly on providing clear goals, support, and praise. Emphasizing the economic exchange focus of contingent reward leadership but also the possibility of contingent sanctions, 
as is done by Podsakoff, Todor, and Skov (1982), could be considered in future research, particularly to look at its effect on controlled motivation.

Fourth, this study focused on the reciprocal influence managers and followers may have on one another. However, the 6-to-18 month time lag used may not be optimal to capture the maximum effect of leadership on motivation (Dormann \& Griffin, 2015), though it is difficult to determine what time lag would be appropriate as they tend to vary from a few weeks to a year across published studies. Since motivation has been shown to display momentary fluctuations (da Motta Veiga \& Gabriel, 2016), it is also possible that leadership variations could impact motivation at a more episodic level, calling for the use of event-sampling methodologies in future research (e.g., Tims et al, 2011). Unfortunately, it was not possible in the context of the present analyses to further assess the possible moderating role of this time lag variation on the observed relations. It would thus appear doubly important for future research to more systematically consider a wider, and more diversified, sets of time lags in order to better document the role played by time in these relations.

Fifth, other sources of influence on leadership behaviors were not taken into account in the present study. For instance, research has shown that pressure from above triggers more controlling behaviors in teachers towards their students (Deci et al., 1982; Pelletier \& Sharp, 2009), and that the work motivation of managers influences their own leadership style (Trépanier, Fernet, \& Austin, 2012). This can also work the other way around. It has been shown, for example, that students who were told that their instructor was getting paid to teach them assumed that the teacher was less intrinsically motivated to teach than students who were told that their teacher volunteered. This affected the students' own intrinsic motivation to learn and to persist on the learning activity (Radel, Sarrazin, Legrain, \& Wild, 2010). What has not yet been investigated is how pressure from above, pressure from below, and even pressure from within (i.e. their own controlled motivation) interact in affecting managers' leadership 
behaviors. Clearly, this is an area that needs to be more thoroughly investigated in future research.

Sixth and finally, caution is warranted regarding the moderation of crisis. This addition to the study was serendipitous and therefore exploratory. Future research could attempt to plan a study, though we have limited ideas on how this could be done in the field. One possibility is to develop metrics to evaluate the levels and types of crises, which would provide more nuanced information about the effects of crises on employees' reactions to leadership when they are captured during research projects. Past research had examined the role of crisis by focusing on the emergence of leaders following disasters, such as earthquakes, hurricanes, terrorist attacks, and wars (Bligh \& Kohles, 2009; Mumford et al., 2007; Waldman \& Yammarino, 1999; Williams et al., 2012), and managers' preferences in times of crisis and non-crisis in organizations (Hunt et al., 1999; Mulder et al., 1971, 1986). In contrast, we focused on potentially less traumatic crises, such as economic downturns, project changes, and labor conflicts. Thus, it is possible that our findings pertain to these levels of crises, and that different effects would be found for more disturbing crises. In addition, the present study considered crisis as a moderator of relations between leadership on employee outcomes, instead of as a predictor of leadership.

Despite these limitations, the present research also offers interesting avenues for future research. For one, it lays the groundwork to develop the concept of collective motivation. Future research could help uncover what would lead to the convergence of motivation amongst subordinates, for example by examining how leadership perceptions and need support influence convergence over time. Moreover, the fact that TFL perceptions had an effect on motivation at the collective level supports the idea that TFL may act mostly at this level, though more research is needed to evaluate if this result is specific to motivation or if it generalizes to other outcomes. Research also needs to uncover the dynamics created among subordinates by exposure to a 
collective TFL climate. In other words, future research could examine the dynamics involved in translating TFL and TSL managerial behaviors into collective motivational outcomes. Factors such as identity, cohesion, supportive peer behaviors, and even peer pressure could be explored as mediating mechanisms (e.g., Steffens et al., 2014). For example, when managers are perceived to act in a transformational manner, it might encourage similar need supportive behaviors amongst subordinates. Indeed, research has already shown that supporting versus controlling teachers influences how they support or control students (Deci, Spiegel, Ryan, Koestner, \& Kauffman, 1982; Pelletier et al., 2002). Conversely, some aspects of TFL perceptions might also create some kind of pressure to conform among employees, which might possibly explain the increase in collective controlled work motivation. Leadership behaviors that strengthen group norms, such as articulating a strong vision and contingently rewarding, could have similar effects at the collective level, essentially creating "corporate cultism" (Tourish \& Pinnington, 2002). It would thus be worthwhile for future research to examine how norms and pressure might be created through TFL climates.

\section{Practical Implications}

Our results support the importance of behaving transformationally in all circumstances to promote the autonomous motivation of subordinates. In particular, the study shows that creating a transformational climate affects the whole collective. Therefore, providing subordinates with a vision in a public manner, encouraging out-of-the-box thinking, and acting as a role model and coach, can contribute to developing their collective autonomous motivation, which so far have been shown to lead to greater individual performance, commitment, and wellbeing (Arnold et al., 2007; Gagné, Chemolli, Forest, \& Koestner, 2008; Slemp et al., 2018). It is therefore advisable to select managers who have characteristics associated with TFL (Judge, Bono, Ilies, \& Gerhardt, 2002) or to train TFL behaviors (Avolio, Reichard, Hannah, Walumbwa, \& Chan, 2009; Collins \& Holton, 2004; Kelloway \& Barling, 2000). 
However, the present study also showed that TSL should not be neglected in times of crisis. If we consider organizations in crisis to be less structured and stable than those not in crisis, path-goal theory (House, 1971) would advise to use more directive leadership styles, closer to TSL. Path-goal theory would also advise using more participative, supportive, and achievement-oriented styles when the environment is more structured and stable. It may thus be advisable for training not to solely focus on teaching TFL, but on coaching managers to adapt their behaviors to the situation. Since controlled motivation also seemed to have some modest influence on individual perceptions of TSL, coaching could also focus on making managers aware of how their behavior may possibly be influenced when subordinates demonstrate substantial controlled motivation, and on alternative ways of acting with them to decrease their controlled motivation. Teacher behaviors supportive of the three psychological needs have been shown to bring about a switch in student motivation from controlled to autonomous, and therefore offers good support for the idea that this is a feasible solution to such motivational problems (Black \& Deci, 2000).

\section{Conclusion}

The present study set out to uncover critical associations between leadership and motivation through the use of rigorous multilevel cross-lagged analyses to disentangle where the effects are located. The study also investigated if organizational crisis moderates these relations. Results showed that collective perceptions of TFL led to increases in both collective autonomous and controlled work motivation. TSL also mattered when considering organizational circumstances, such that it helped achieve better individual and collective motivation when organizations were experiencing a crisis, and it worsened individual motivation when organizations were not in crisis. There was little evidence that motivation changed perceptions of leadership.

\section{Footnotes}


${ }^{1}$ This questionnaire was used with the authorization of Mind Garden. Sample items can be obtained from Mind Garden.

${ }^{2}$ We re-estimated our main two-level models (reported in Table 2) when adding followers' characteristics (gender, age, and tenure) as controls in the Level 1 part of the model. The results obtained as part of these additional analyses fully match those reported here, consistent with a lack of biasing effects of control variables and with the natural robustness of autoregressive cross lagged models to the omission of controls. It was not possible, due to the aforementioned convergence difficulties, to incorporate these controls at Level 2, or in the three-level model used to test for the effects of crisis.

\section{References}

Antonakis, J., Avolio, B. J., Sivasubramaniam, N. (2003). Context and leadership: an examination of the nine-factor full-range leadership theory using the Multifactor Leadership Questionnaire. Leadership Quarterly, 14, 261-295.

Antonakis, J., Bendahan, S., Jacquart, P., \& Lalive, R. (2014). Causality and endogeneity: Problems and solutions. In D. V. Day (Ed.), Oxford handbook of leadership and organizations (pp. 93-117). New York, NY: Oxford University Press.

Arnold, K.A., Turner, N., Barling, J., Kelloway, E. K., \& McKee, M. C. (2007).

Transformational leadership and psychological well-being: the mediating role of meaningful work. Journal of occupational Health Psychology, 12, 193-203.

Asparouhov, T. (2005). Sampling weights in latent variable modeling. Structural Equation Modeling, 12, 411-434.

Asparouhov, T., Hamaker, E.L. \& Muthen, B. (2018). Dynamic structural equation models. Structural Equation Modeling, 25, 359-388,

Avolio, B.J., Bass, B.M., \& Jung, D.I. (1999). Re-examining the components of transformational and transactional leadership using the multifactor leadership questionnaire. Journal of Occupational and Organizational Psychology, 72, 441-462. 
Avolio, B. J., Reichard, R. J., Hannah, S. T., Walumbwa, F. O., Chan, A. (2009). A metaanalytic review of leadership impact research: Experimental and quasi-experimental studies. Leadership Quarterly, 20, 764-784.

Avolio, B. J., \& Yammarino, F. (1990). Operationalizing charismatic leadership using a level of analysis framework. Leadership Quarterly, 1, 193-208.

Avolio, B. J., Zhu, W., Koh, W., \& Bhatia, P. (2004). Transformational leadership and organizational commitment: mediating role of psychological empowerment and moderating role of structural distance. Journal of Organizational behavior, 25, 951- 968.

Barrick, M. R., Thurgood, G. R., Smith, T. A., \& Courtright, S. H. (2015). Collective organizational engagement: Linking motivational antecedents, strategic implementation, and firm performance. Academy of Management Journal, 58, 111-135.

Bass, B.M. (1985). Leadership and performance beyond expectations. NY, NY: Free Press.

Bass, B. M., \& Avolio, B. J. (1994). Improving organizational effectiveness through transformational leadership. Thousand Oaks, CA: Sage.

Bass, B. M., \& Avolio, B. J. (1995). The Multifactor Leadership Questionnaire. Palo Alto, CA: Mind Garden.

Bass, B.M., \& Riggio, R.E. (2006). Transformational Leadership (2nd ed.). Mahwah, NJ: Lawrence Erlbaum.

Black, A. E., \& Deci, E. L. (2000). The effects of instructors' autonomy support and students' autonomous motivation on learning organic chemistry: A self-determination theory perspective. Science Education, 84, 740-756.

Bliese, P. D. (2000). Within-group agreement, non-independence, and reliability: Implications for data aggregation and analysis. In K.J. Klein \& S.W. Kozlowski (Eds.), Multilevel Theory, Research, and Methods in Organizations (pp. 349-381). San Francisco, CA: Jossey-Bass.

Bliese, P. D., Maltarich, M. A., \& Hendricks, J. L. (2018). Back to basics with mixed-effects 
models: Nine take-away points. Journal of Business and Psychology, 33, 1-23.

Bligh, M. C., \& Kohles, J. C. (2009). The enduring allure of charisma: How Barack Obama won the historic 2008 presidential election. The Leadership Quarterly, 20, 483-492.

Boehm, A., Enoshm, G., \& Michal, S. (2010). Expectations of grassroots community leadership in times of normality and crisis. Journal of Contingencies \& Crisis Management, 18, 184-194.

Bollen, K. A. (1989). Structural equations with latent variables. New York: Wiley

Bono, J., \& Judge, T. (2003). Self-concordance at work: Toward understanding the motivational effects of transformational leaders. Academy of Management Journal, 46, 554-571.

Boudrias, J.-S., Morin, A.J.S., \& Lajoie, D. (2014). Directionality of the associations between psychological empowerment and behavioral involvement: A longitudinal autoregressive cross lagged analysis. Journal of Occupational and Organizational Psychology, 87, 437-463.

Braun, S., Peus, C., Weisweiler, S., Frey, D. (2013). Transformational leadership, job satisfaction, and team performance: A multilevel mediation model of trust. Leadership Quarterly, 24, 270-283.

Breevaart, K., Bakker, A., Hetland, J., Demerouti, E., Olsen, O., \& Espevik, R. (2014). Daily transactional and transformational leadership and daily employee engagement. Journal of Occupational and Organizational Psychology, 87, 138-157.

Charbonneau, D., Barling, J. and Kelloway, E. K. (2001). Transformational leadership and sports performance: the mediating role of intrinsic motivation. Journal of Applied Social Psychology, 31, 1521-1534.

Charbonnier-Voirin, A., El Akremi, A., \& Vandenberghe, C. (2010). A multilevel model of transformational leadership and adaptive performance and the moderating role of climate for innovation. Group and Organization Management, 35, 699-726.

Chen, F., Bollen, K.A., Paxton, P., Curran, P.J., \& Kirby, J.B. (2001). Improper solutions in structural question models. Sociological Methods \& Research, 29, 468-508. 
Chen, G., Fahr, J.-L., Campbell-Bush, E. M., Wu, Z., \& Wu, X. (2013). Teams as innovative systems: Multilevel motivational antecedents of innovation in R\&D teams. Journal of Applied Psychology, 98, 1018-1027.

Chun, J. U., Yammarino, F. J., Dionne, S. D., Sosik, J. J., \& Moon, H. K. (2009). Leadership across hierarchical levels: Multiple levels of management and multiple levels of analysis. Leadership Quarterly, 20, 689-707.

Cohen, J. (1988). Statistical power analysis for the behavioral sciences. Mahwah, NJ: Erlbaum.

Collins, D. B., \& Holton, E. F. (2004). The effectiveness of managerial leadership development programs: A meta-analysis of studies from 1982 to 2001. Human Resource Development Quarterly, 15, 217-248.

Conger, J. A. (1999). Charismatic and transformational leadership in organizations: An insider's perspective on these developing streams of research. Leadership Quarterly, 10, 145-179.

da Motta Veiga, S. P., \& Gabriel, A. S. (2016). The role of self-determined motivation in job search: A dynamic approach. Journal of Applied Psychology, 101, 350-361.

Day, D. V. (2014). Oxford handbook of leadership and organizations. New York: Oxford University Press.

DeCelles, K. A., Tesluk, P. E., Taxman, F. S. (2013). A field investigation of multilevel cynicism toward change. Organization Science, 24, 154-171.

Deci, E. L., Koestner, R., \& Ryan, R. M. (1999). A meta-analytic review of experiments examining the effects of extrinsic rewards on intrinsic motivation. Psychological Bulletin, 125, 627-668.

Deci, E. L., \& Ryan, R. M. (1985). Intrinsic motivation and self-determination in human behavior. New York, NY: Plenum.

Deci, E. L., \& Ryan, R. M. (2000). The "what" and "why" of goal pursuits: Human needs and the self-determination of behavior. Psychological Inquiry, 11, 227-268.

Deci, E. L., \& Ryan, R. M. (2008). Facilitating optimal motivation and psychological well-being 
across life's domains. Canadian Psychology, 49, 14-23.

Deci, E. L., Ryan, R. M., Gagné, M., Leone, D. R., Usunov, J., \& Kornazheva, B. P. (2001). Need satisfaction, motivation, and well-being in the work organizations of a former Eastern Bloc country. Personality and Social Psychology Bulletin, 27, 930-942.

Deci, E.L., Spiegel, N.H., Ryan, R.M., Koestner, R., \& Kauffman, M. (1982). Effects of performance standards on teaching styles: Behavior of controlling teachers. Journal of Educational Psychology, 74, 852-859.

DeGroot, T., Kiker, D. S., \& Cross, T. (2000). A meta-analysis to review organizational outcomes related to charismatic leadership. Canadian Journal of Administrative Sciences, 17, 356-371.

Den Hartog, D. N., Van Muijen, J. J., Koopman, P. L. (1997). Transactional versus transformational leadership: An analysis of the MLQ. Journal of Occupational and Organizational Psychology, 70, 19-34.

Dormann, C., \& Griffin, M. A. (2015). Optimal time lags in panel studies. Psychological Methods, 20, 489-505.

Enders, C. K., (2010). Applied missing data analysis. New York: Guilford

Eyal, O., \& Roth, G. 2011. Principals' leadership and teachers' motivation: Self-determination theory analysis. Journal of Educational Administration, 49, 256-275.

Fernet, C., Austin, S., Gagné, M., \& Forest, J. (2015). Extending the scope of the motivational effect of transformational leadership on employee functioning: The role of employees' perceived job characteristics and motivation. Work and Stress, 29, 11-31.

Fulmer, A. \& Ostroff, C. (2016). Convergence and emergence in organizations: An integrative framework and review. Journal of Organizational Behavior, S1, S122-S145.

Gagné, M. (2014). Oxford handbook of employee engagement, motivation, and selfdetermination theory. New York: NY: Oxford University Press.

Gagné, M. (2018). From strategy to action: Transforming organizational goals into 
organizational behavior. International Journal of Management Review, 20, S83-S104.

Gagné, M., Chemolli, E., Forest, J., \& Koestner, R. (2008). The temporal relations between work motivation and organizational commitment. Psychologica Belgica, 48, 219-241.

Gagné, M., \& Deci, E. L. (2005). Self-determination theory and work motivation. Journal of Organizational Behavior, 26, 331-362.

Gagné, M., Forest, J., Vansteenkiste, M., Crevier-Braud, L., Van den Broeck, A., et al. (2015). The Multidimensional Work Motivation Scale: Validation evidence in seven languages and nine countries. European Journal of Work and Organizational Psychology, 24, 178-196.

Gagné, M., Koestner, R., \& Zuckerman, M. (2000). Facilitating acceptance of organizational change: Importance of self-determination. Journal of Applied Social Psychology, 30, 1843-1852.

Gooty, J., Gavin, M., Johnson, P., Frazier, M., \& Snow, D. (2009). In the eyes of the beholder: Transformational leadership, positive psychological capital, and performance. Journal of Leadership \& Organization Studies, 15, 353-367.

Graham, J. W. (2009). Missing data analysis: Making it work in the real world. Annual Review of Psychology, 60, 549-576.

Grimm, K.J., Ram, N., \& Estabrook, R. (2017). Growth modelling: Structural equation and multilevel approaches. New York: Guilford.

Hedges, L. V., \& Hedberg, E. C. (2007). Intraclass correlation values for planning grouprandomized trials in education. Educational Evaluation \& Policy Analysis, 29, 60-87.

Heinitz, K., Liepmann, D., \& Felfe, J. (2005). Examining the factor structure of the MLQ: Recommendation for a reduced set of factors. European Journal of Psychological Assessment, 21, 182-190.

Hetland, H., Hetland, J., Andreassen, C. S., Pallessen, S., \& Notelaers, G. (2011). Leadership and fulfillment of the three basic psychological needs at work. Career Development International, 16, 507-523. 
Hinkin, T. R., \& Schriescheim, C. A. (2008). Atheoretical and empirical examination of the transactional and non-leadership dimensions of the Multifactor Leadership Questionnaire (MLQ). Leadership Quarterly, 19, 501-513.

Hoffman, B.J., Bynum, B.H., Piccolo, R.F., \& Sutton, A.W. (2011). Person-organization value congruence: How transformational leaders influence work group effectiveness. Academy of Management Journal, 54, 779-796.

House, R. J. (1971). A path goal theory of leader effectiveness. Administrative Sciences Quarterly, 16, 321-339.

Howard, J., Gagné, M., Morin, A. J. S., \& Van den Broeck, A. (2016). Motivation profiles at work: A self-determination theory approach. Journal of Vocational Behavior, 95, 74-89.

Hsu, H.-Y. (2009). Testing the effectiveness of various commonly used fit indices for detecting misspecifications in multilevel structural equation models. Unpublished doctoral thesis, Texas A\&M University, TX, USA.

Hunt, J. G., Boal, K. B., \& Dodge, G. E. (1999). The effects of visionary and crisis-responsive charisma on followers: An experimental examination of two kinds of charismatic leadership. Leadership Quarterly, 10, 423-448.

Jöreskog, K.G. (1979). Statistical models and methods for the analysis of longitudinal data. In K.G. Jöreskog \& D. Sörbom (Eds.), Advances in Factor Analysis and Structural Equation Models. Cambridge, MA: Abt Books.

Joyce, W. F., \& Slocum, J. W. Jr (1984). Collective climate: Agreement as a basis for defining aggregate climates in organizations. Academy of Management Journal, 27, 721-742.

Judge, T. A., Bono, J. E., Ilies, R., \& Gerhardt, M. (2002). Personality and leadership: A qualitative and quantitative review. Journal of Applied Psychology, 87, 765-780.

Kahn, W. A., Barton, M. A., \& Fellows, S. (2013). Organizational crises and the disturbance of relational systems. Academy of Management Review, 38, 377-396. 
Katz, R. (1977). The influence of group conflict on leadership effectiveness. Organizational Behavior and Human Performance, 20, 265-286.

Kelloway, E.K., \& Barling, J. (2000). What we've learned about developing transformational leaders. The Leadership and Organization Development Journal, 21, 157-161.

Kovajnic, S., Schuh, S. C., Klaus, J., Van Quaquebeke, N., Van Dick, R. (2012). How do transformational leaders foster positive employee outcomes? A self-determination-based analysis of employees' needs as mediating links. Journal of Organizational Behavior, 33, 1031-1052.

Kovajnic, S., Schuh, S. C., \& Jonas, K. (2013). Transformational leadership and performance: An experimental investigation of the mediating effects of basic needs satisfaction and work engagement. Journal of Occupational and Organizational Psychology, 86, 543-555.

Kozlowski, S. W. J. (2012). Groups and teams in organizations: Studying the multilevel dynamics of emergence. In A. B. Hollingshead \& M. S. Poole (Eds.), Methods for studying small groups: A behind-the-scenes guide (pp. 260-283). New York: Routledge.

Kozlowski, S.W.J., Mak, S., \& Chao, G.T. (2016). Team-centric leadership: An integrative review. Annual Review of Organizational Psychology and Organizational Behavior, 3, 21-54.

Liao, H., \& Chuang, A. (2007). Transforming service employees and climate: A multilevel, multisource examination of transformational leadership in building long-term service relationships. Journal of Applied Psychology, 92, 1006-1019.

Lowe, K.B., Kroeck, K.G., \& Sivasubramaniam, N. (1996). Effectiveness correlates of transformational and transactional leadership: A meta-analytic review of the MLQ literature. Leadership Quarterly, 7, 385- 425.

Lüdtke, O., Marsh, H.W., Robitzsch, A., Trautwein, U., Asparouhov, T., \& Muthén, B.O. (2008). The Multilevel Latent Covariate Model: A New, More Reliable Approach to GroupLevel Effects in Contextual Studies. Psychological Methods, 13, 203-229.

Lüdtke, O., Marsh, H.W., Robitzsch, A., \& Trautwein, U. (2011). A 2 X 2 Taxonomy of 
Multilevel Latent Contextual Models: Accuracy-Bias Trade-Offs in Full and Partial Error Correction Models. Psychological Methods, 16, 444-467.

Markham, S. E., Yammarino, F. J., Murry, W. D., \& Palanski, M. E. (2010). Leader-member exchange, shared values, and performance: Agreement and levels of analysis do matter. The Leadership Quarterly, 21, 469-480.

Marsh, H. W., Lüdtke, O., Robitzsch, A., Trautwein, U., Asparouhov, T., Muthén, B. O., \& Nagengast, B. (2009). Doubly-latent models of school contextual effects: Integrating multilevel and structural equation approaches to control measurement and sampling error. Multivariate Behavioral Research, 4, 764-802.

Marsh, H. W., Lüdtke, O., Nagengast, B., Trautwein, U., Morin, A. J. S., Abduljabbar, A. S. \& Köller, O. (2012). Classroom climate and contextual effects: Conceptual and methodological issues in the evaluation of group-level effects. Educational Psychologist, 47, 106-124.

Marsh, H. W., Seaton, M., Kuyper, H., Dumas; F., Huguet, P., Regner, I., Buunk, A. P., Monteil, J. M, Blanton, H., Gibbons, F. X. (2010). Phantom behavioral assimilation effects: Systematic biases in social comparison choice studies. Journal of Personality, 78, 671-710.

Matthieu, J. E., Hollenbeck, J. R., van Knippenberg, D., \& Ilgen, D. R. (2017). A century of work teams in the Journal of Applied Psychology. Journal of Applied Psychology, 102, 452-467.

McArdle, McArdle, J. J. (2009). Latent variable modeling of differences in changes with longitudinal data. Annual Review of Psychology, 60, 577-605.

McDonald, R. P. (1970). Theoretical foundations of principal factor analysis and alpha factor analysis. British Journal of Mathematical and Statistical Psychology, 23, 1-21.

Meredith, W. (1993). Measurement invariance, factor analysis and factorial invariance. Psychometrika, 58, 525-543.

Meyer, J. P., \& Gagné, M. (2008). Employee engagement from a self-determination theory perspective. Industrial and Organizational Perspectives, 1, 60-62. 
Millsap, R. (2011). Statistical approaches to measurement invariance. NY: Taylor \& Francis.

Morgeson, F. P., Mitchell, T. R., \& Liu, D. (2015). Event system theory: An event-oriented approach to the organizational sciences. Academy of Management Review, 40, 515-537.

Morin, A.J.S., Maïano, C., Marsh, H.W., Janosz, M., \& Nagengast, B. (2011). The longitudinal interplay of adolescents' self-esteem and body image: A conditional autoregressive latent trajectory. Multivariate Behavioral Research, 46, 157-201.

Morin, A.J.S., Marsh, H.W., Nagengast, B., \& Scalas, L.F. (2014). Doubly latent multilevel analyses of classroom climate: An illustration. The Journal of Experimental Education, 82, 143-167.

Morin, A.J.S., Meyer, J.P., Bélanger, É., Boudrias, J.-S., Gagné, M., \& Parker, P.D. (2016). Longitudinal associations between employees' perceptions of the quality of the change management process, affective commitment to change and psychological empowerment. Human Relations, 69, 839-867.

Mulder, M., Ritsema van Eck, J. R., \& de Jong, R. D. (1971). An organization in crisis and noncrisis situations. Human Relations, 24, 19-41.

Mulder, M., de Jong, R. D., Koppelaar, L., \& Verhage, J. (1986). Power, situation, and leaders' effectiveness: An organizational field study. Journal of Applied Psychology, 71, 566-570.

Mumford, M. D., Friedrich, T. L., Caughron, J. J., \& Byrne, C. L. (2007). Leader cognition in real-world settings: How do leaders think about crises? Leadership Quarterly, 18, 515-543.

Muthén, L., \& Muthén, B. (2014). Mplus user's guide, V.7.2. Los Angeles: Muthén \& Muthén. Nemanich, L. A., Keller, R. T. (2007). Transformational leadership in an acquisition: A field study of employees. Leadership Quarterly, 18, 49-68.

Pearson, C. M., \& Clair, J. A. (1998). Reframing crisis management. Academy of Management Review, 23, 59-76.

Pelletier, L.G., Séguin-Lévesque, C., \& Legault, L. (2002). Pressure from above and pressure from below as determinants of teachers' motivation and teaching behaviors. Journal of 
Educational Psychology, 94, 186-196.

Pelletier, L. G., \& Sharp, E. C. (2009). Administrative pressures and teachers' interpersonal behaviour in the classroom. Theory and Research in Education, 7, 174-183.

Pelletier, L. G., \& Vallerand, R. J. (1996). Supervisors' beliefs and subordinates' intrinsic motivation: A behavioral confirmation analysis. Journal of Personality and Social Psychology, 71, 331-340.

Pillai, R., \& Meindl, J. R. (1998). Context and charisma: A “meso" level examination of the relationship of organic structure, collectivism, and crisis to charismatic leadership. Journal of Management, 24, 643-664.

Podsakoff, P. M., Todor, W. D., \& Skov, R. (1982). Effects of leader performance contingent and non-contingent reward and punishment behaviors on subordinate performance and satisfaction. Academy of Management Journal, 25, 812-821.

Radel, R., Sarrazin, P., Legrain, P., Wild, T. (2010). Social contagion of motivation between teacher and student: Analyzing underlying processes. Journal of Educational Psychology, 102, 577-587.

Rafferty, A. E., \& Griffin, M. A. (2004). Dimensions of transformational leadership: Conceptual and empirical extensions. Leadership Quarterly, 15, 329-354.

Raudenbush, S.W., \& Bryk, A. (2002). Hierarchical linear models (2 ${ }^{\text {nd }}$ ed.). Thousand Oaks: Sage.

Raykov, T., \& Marcoulides, G. A. (2004). Using the Delta Method for Approximate Interval Estimation of Parametric Functions in Covariance Structure Models. Structural Equation Modeling, 11, 659-675.

Reeve, J., \& Jang, H. (2006). What teachers say and do to support students' autonomy during a learning activity. Journal of Educational Psychology, 98, 209-218.

Ryu, E., \& West, S.G. (2009). Level-specific evaluation of model fit in multilevel structural equation modeling. 16, 583-601.

Sarrazin, P.G., Tessier, D.P., Pelletier, L.G., Trouilloud, D.O., \& Chanal, J.P. (2006). The effects of 
teachers' expectations about students' motivation on teachers' autonomy-supportive and controlling behaviors. International Journal of Sport and Exercise Psychology, 4, 283-301.

Sarros, J. C., Tanewski, G. A., Winter, R. P., Santora, J. C., \& Densten, I. L. (2002). Work alienation and organizational leadership. British Journal of Management, 13, 285-304.

Shamir, B., House, R. J., \& Arthur, M. B. (1993). The motivational effects of charismatic leadership: A self-concept based theory. Organization Science, 4, 577-594.

Slemp, G. R., Kern, M. L., Patrick, K. J., \& Ryan, R. M. (2018). Leader autonomy support in the workplace: A meta-analytic review. Motivation and Emotion, 42, 706-724.

Stam, D., van Knippenberg, D., Wisse, B., \& Nederveen Pieterse, A. (2018). Motivation in words: Promotion- and prevention-oriented leader communication in times of crisis. Journal of Management, 44, 2859-2887.

Steffens, N. K., Haslam, S. A., Reicher, S. D., Platow, M. J., Fransen, K., Yang, J., et al. (2014). Leadership as social identity management: Introducing the Identity Leadership Inventory (ILI) to assess and validate a four-dimensional model. Leadership Quarterly, 25, 1001-1024.

Tejeda, M. J., Scandura, T. A., \& Pillai, R. (2001). The MLQ revisited: Psychometric properties and recommendations. Leadership Quarterly, 12, 31-52.

Tims, M., Bakker, A. B., Xanthopoulou, D. (2011). Do transformational leaders enhance their followers' daily work engagement? Leadership Quarterly, 22, 121-131.

Tourish, D., \& Pinnington, A. (2002). Transformational leadership, corporate cultism and the spirituality paradigm: An unholy trinity in the workplace? Human Relations, 55, 147-172.

Trépanier, S.-G., Fernet, C., \& Austin, S. (2012). Social and motivational antecedents of perceptions of transformational leadership: A self-determination theory perspective. Canadian Journal of Behavioural Science, 44, 272-277.

Van den Broeck, A., Ferris, D. L., Chang, C.-H., \& Rosen, C. (2016). A review of self-determination theory's basic psychological needs at work. Journal of Management, 42, 1195-1229. 
van Knippenberg, D., \& Sitkin, S. B. (2013). A critical assessment of charismatictransformational leadership research: Back to the drawing board? Academy of Management Annals, 7, 1-60.

Waldman, D. A., Ramirez, G. G., House, R. J., \& Puranam, P. (2001). Does leadership matter? CEO leadership attributes and profitability under conditions of perceived environmental uncertainty. Academy of Management Journal, 44, 134-143.

Waldman, D., \& Yammarino, F. (1999). CEO charismatic leadership: Levels-of-management and levels-of-analysis effects. Academy of Management Review, 24, 266-285.

Wang, Z. N., \& Gagné, M. (2013). A Chinese-Canadian Cross-cultural Investigation of Transformational Leadership, Autonomous Motivation and Collectivistic Value. Journal of Leadership and Organization Studies, 20, 134-142.

Wang, X. H., \& Howell, J. M. (2012). A multilevel study of transformational leadership, identification, and follower outcomes. Leadership Quarterly, 23, 775-790.

Weick, K. E. (1995). Sensemaking in organizations. Thousand Oaks, CA: Sage.

Williams, E. A., Pillai, R., Deptula, B., \& Lowe, K. B. (2012). The effects of crisis, cynicism about change, and value congruence on perceptions of authentic leadership and attributed charisma in the 2008 presidential election. Leadership Quarterly, 23, 324-341.

Wofford, J. C., Whittington, J. L., \& Goodwin, V. L. (2001). Follower motive patterns as situational moderators for transformational leadership effectiveness. Journal of Managerial Issues, 13, 196-211.

Yammarino, F.J., \& Bass, B. M. (1990). Transformational Leadership and Multiple Levels of Analysis. Human Relations, 43, 975-995.

Yukl, G. (1999). An evaluation of conceptual weaknesses in transformational and charismatic leadership theories. Leadership Quarterly, 10, 285-305.

Yukl, G. (2002). Leadership in organizations. Upper Saddle River, NJ: Prentice-Hall. 
Table 1

Latent Variable Correlations from the Final Strictly Invariant Measurement Model

\begin{tabular}{|c|c|c|c|c|c|c|c|c|c|c|c|c|c|c|c|}
\hline & Gender & Age & Tenure & TFL-T1 & TSL-T1 & PAL-T1 & Amot.-T1 & Contr.-T1 & Auton.-T1 & TFL-T2 & TSL-T2 & PAL-T2 & Amot.-T2 & Contr.-T2 & Auton.-T2 \\
\hline \multicolumn{16}{|c|}{ - } \\
\hline \multicolumn{16}{|c|}{ Demographics } \\
\hline \multicolumn{16}{|c|}{ Gender } \\
\hline Age & $0.168 * *$ & & $0.168 * *$ & & & & & & & & & & & & \\
\hline Tenure & 0.033 & $0.561 * *$ & 0.033 & & & & & & & & & & & & \\
\hline \multicolumn{16}{|c|}{ Latent Factors } \\
\hline TFL-T1 & 0.057 & 0.045 & 0.002 & & & & & & & & & & & & \\
\hline TSL-T1 & $-0.205^{* *}$ & -0.024 & -0.093 & 0.071 & & & & & & & & & & & \\
\hline PAL-T1 & $-0.144^{* *}$ & -0.049 & 0.034 & $-0.616^{* *}$ & $0.112 * *$ & & & & & & & & & & \\
\hline Amot.-T1 & -0.036 & $-0.179^{* *}$ & $-0.220^{* *}$ & $-0.171 * *$ & $0.147^{* *}$ & $0.191 * *$ & & & & & & & & & \\
\hline Contr.-T1 & -0.005 & $-0.095^{*}$ & $-0.227^{* *}$ & $0.208 * *$ & $0.149 * *$ & -0.045 & 0.013 & & & & & & & & \\
\hline Auton.-T1 & $0.136^{*}$ & $0.195^{* *}$ & 0.131 & $0.460 * *$ & -0.011 & $-0.299 * *$ & $-0.379 * *$ & $0.239 * *$ & & & & & & & \\
\hline TFL-T2 & 0.059 & 0.060 & -0.006 & $0.614 * *$ & -0.008 & $-0.392 * *$ & $-0.129 * *$ & $0.241 * *$ & $0.376^{* *}$ & & & & & & \\
\hline TSL-T2 & $-0.213^{* *}$ & -0.025 & -0.023 & $0.198 * *$ & $0.589 * *$ & -0.032 & 0.087 & 0.102 & 0.038 & $0.310^{* *}$ & & & & & \\
\hline PAL-T2 & $-0.280^{* *}$ & $-0.089^{*}$ & 0.095 & $-0.242 * *$ & $0.294 * *$ & $0.447 * *$ & 0.111 & 0.050 & $-0.224 * *$ & $-0.363 * *$ & $0.597 * *$ & & & & \\
\hline Amot.-T2 & 0.012 & $-0.172^{* *}$ & $-0.173^{*}$ & $-0.145^{*}$ & 0.014 & $0.216^{* *}$ & $0.655 * *$ & -0.044 & $-0.222 * *$ & $-0.195 * *$ & -0.055 & 0.079 & & & \\
\hline Contr.-T2 & 0.089 & $-0.083^{*}$ & $-0.187^{* *}$ & $0.164 * *$ & -0.027 & -0.005 & 0.033 & $0.616 * *$ & $0.171^{* *}$ & $0.320 * *$ & 0.047 & -0.033 & 0.008 & & \\
\hline Auton.-T2 & 0.093 & $.0183^{* *}$ & 0.051 & $0.407 * *$ & 0.044 & $-0.231 * *$ & $-0.247 * *$ & $0.243 * *$ & $0.710 * *$ & $0.548 * *$ & $0.167 * *$ & $-0.190 * *$ & $-0.397 * *$ & $0.319 * *$ & \\
\hline$\omega$ & --- & --- & --- & .965 & .678 & .923 & .787 & .858 & .908 & .968 & .679 & .923 & .754 & .850 & .913 \\
\hline ICC 1 & --- & --- & --- & .205 & .182 & .207 & .096 & .085 & .157 & .234 & .252 & .403 & .086 & .060 & .168 \\
\hline ICC2 & --- & --- & --- & .653 & .618 & .655 & .435 & .404 & .576 & .691 & .711 & .831 & .407 & .319 & .596 \\
\hline
\end{tabular}

$* p<.05 ; * *<.01$. Note: TFL $=$ Transformational Leadership; TSL = Transactional Leadership; LS = Laissez-Faire Leadership; Amot. $=$ Amotivation; Contr. $=$ Controlled Motivation; Auton. $=$ Autonomous Motivation; T1 $=$ Time 1; T2 $=$ Time 2; Stability coefficients are represented in bold. In this Table, correlations among the key variables used in the present study (TFL, TSL, LS, Amot, Contr., and Auton.) are latent variables correlations saved from preliminary measurement models in which these latent factors were estimated in standardized units $(\mathrm{M}=0, \mathrm{SD}=1)$. For purposes of the main analyses, factors scores (in the same standardized units) were saved from these models. 
Table 2

Results from the Complete Multilevel Predictive Cross Lagged Model

\begin{tabular}{|c|c|c|c|c|c|c|c|}
\hline \multirow[b]{2}{*}{ Predictor (T1) } & \multirow[b]{2}{*}{ Outcome (T2) } & \multicolumn{3}{|c|}{ Individual-Level (Level 1) } & \multicolumn{3}{|c|}{ Group-Level (Level 2) } \\
\hline & & $b$ (s.e.) & $\beta$ (s.e.) & ES (s.e.) & $b$ (s.e.) & $\beta$ (s.e.) & ES (s.e.) \\
\hline \multicolumn{8}{|l|}{ Predictive Paths } \\
\hline Transactional Leadership & Amotivation & $-0.006(0.023)$ & $-0.006(0.021)$ & $-0.006(0.022)$ & $0.031(0.187)$ & $0.014(0.082)$ & $0.014(0.086)$ \\
\hline Transactional Leadership & Controlled Motivation & $-0.015(0.025)$ & $-0.013(0.021)$ & $-0.013(0.022)$ & $-0.201(0.108)$ & $-0.082(0.044)$ & $-0.085(0.046)$ \\
\hline Transactional Leadership & Autonomous Motivation & $0.015(0.027)$ & $0.012(0.021)$ & $0.013(0.023)$ & $-0.232(0.224)$ & $-0.084(0.081)$ & $-0.092(0.089)$ \\
\hline Passive Leadership & Amotivation & $0.015(0.019)$ & $0.015(0.019)$ & $0.016(0.020)$ & $0.023(0.108)$ & $0.012(0.057)$ & $0.013(0.059)$ \\
\hline Passive Leadership & Controlled Motivation & $0.026(0.015)$ & $0.025(0.015)$ & $0.025(0.015)$ & $0.132(0.106)$ & $0.064(0.052)$ & \\
\hline Passive Leadership & Autonomous Motivation & $-0.018(0.029)$ & $-0.016(0.025)$ & $-0.017(0.027)$ & $0.155(0.090)$ & $0.067(0.039)$ & $0.073(0.043)$ \\
\hline Transformational Leadership & Amotivation & $0.011(0.032)$ & $0.012(0.034)$ & $0.012(0.035)$ & $-0.046(0.185)$ & $-0.024(0.098)$ & $-0.025(0.103)$ \\
\hline Transformational Leadership & Controlled Motivation & $-0.020(0.050)$ & $-0.019(0.048)$ & $0.020(0.050)$ & $0.226(0.106)^{*}$ & $0.112(0.053)^{*}$ & $0.115(0.054)^{*}$ \\
\hline Transformational Leadership & Autonomous Motivation & $-0.017(0.046)$ & $-0.015(0.040)$ & $-0.016(0.044)$ & $0.369(0.173)^{*}$ & $0.161(0.075)^{*}$ & $0.177(0.083)^{*}$ \\
\hline \multicolumn{8}{|l|}{ Reciprocal Paths } \\
\hline Amotivation & Transactional Leadership & $-0.019(0.034)$ & $-0.014(0.025)$ & $-0.016(0.029)$ & $0.322(0.511)$ & $0.077(0.122$ & $0.089(0.142)$ \\
\hline Amotivation & Passive Leadership & $-0.020(0.034)$ & $-0.016(0.026)$ & $-0.020(0.033)$ & $-0.400(1.373)$ & $-0.099(0.341)$ & $-0.129(0.441)$ \\
\hline Amotivation & Transformational Leadership & $-0.011(0.025)$ & $-0.010(0.023)$ & $-0.011(0.026)$ & $0.694(0.633)$ & $0.205(0.187)$ & $0.234(0.214)$ \\
\hline Controlled Motivation & Transactional Leadership & $0.044(0.020)^{*}$ & $0.033(0.015)^{*}$ & $0.039(0.018)^{*}$ & $0.018(0.450)$ & $0.004(0.104)$ & $0.005(0.120)$ \\
\hline Controlled Motivation & Passive Leadership & $-0.029(0.050)$ & $-0.023(0.039)$ & $-0.029(0.050)$ & 0.382 & 0.092 & $0.118(0$ \\
\hline Controlled Motivation & Transformational Leadership & $0.096(0.050)$ & $0.090(0.046)$ & $0.103(0.053)$ & $139(0.502)$ & $-0.040(0.143)$ & $-0.045(0.163)$ \\
\hline Autonomous Motivation & Transactional Leadership & $0.036(0.024)$ & $0.027(0.018)$ & $0.031(0.021)$ & $-0.230(0.548)$ & $-0.075(0.178)$ & $-0.086(0.206)$ \\
\hline Autonomous Motivation & Passive Leadership & $-0.005(0.041)$ & $-0.004(0.032)$ & $-0.005(0.041)$ & $-0.579(1.345)$ & $-0.195(0.452)$ & $-0.252(0.585)$ \\
\hline Autonomous Motivation & Transformational Leadership & $0.049(0.047)$ & $0.045(0.044)$ & $0.051(0.050)$ & $0.134(0.632)$ & $0.053(0.252)$ & $0.061(0.288)$ \\
\hline \multicolumn{8}{|l|}{ Autoregressive paths } \\
\hline Amotivation & Amotivation & $0.761(0.022)^{* *}$ & $0.844(0.025)^{* *}$ & $0.883(0.026)^{* *}$ & $-0.096(0.151)$ & $-0.035(0.055)$ & $-0.036(0.057)$ \\
\hline Controlled Motivation & Controlled Motivation & $0.714(0.041)^{* *}$ & $0.758(0.044)^{* *}$ & $0.782(0.045)^{* *}$ & $-0.189(0.120)$ & $-0.061(0.039)$ & $-0.063(0.040)$ \\
\hline Autonomous Motivation & Autonomous Motivation & $0.774(0.013)^{* *}$ & $0.719(0.012)^{* *}$ & $0.789(0.013)^{* *}$ & $-0.023(0.220)$ & $-0.009(0.088)$ & $-0.010(0.097)$ \\
\hline Transactional Leadership & Transactional Leadership & $0.993(0.053)^{* *}$ & $0.615(0.033)^{* *}$ & $0.711(0.038)^{* *}$ & $1.276(0.623)^{*}$ & $0.372(0.182)^{*}$ & $0.430(0.210)^{*}$ \\
\hline Passive Leadership & Passive Leadership & $0.604(0.137)^{* *}$ & $0.428(0.097)^{* *}$ & $0.554(0.126)^{* *}$ & $1.473(0.425)^{* *}$ & $0.534(0.154)^{* *}$ & $0.691(0.199)^{* *}$ \\
\hline Transformational Leadership & Transformational Leadership & $0.623(0.106)^{* *}$ & $0.533(0.090)^{* *}$ & $0.609(0.103)^{* *}$ & $1.172(0.509)^{*}$ & $0.509(0.221)^{*}$ & $0.582(0.253)^{*}$ \\
\hline \multicolumn{8}{|c|}{$\begin{array}{l}* \mathrm{p} \leq .05 ; * * \mathrm{p} \leq .01 ; b=\text { Unstandardized regression coefficient; s.e. }=\text { Standard error of the coefficient; } \beta=\text { Standardized coefficient properly calculated in relation to the total } \\
\text { variance (e.g., Marsh et al., 2009, 2012; Morin et al., 2014); ES = Effect size indicator calculated as } b^{*} S D_{\text {predictor }} / S D_{\text {outcome }}, \text { where } S D_{\text {predictor }} \text { is the standard deviation of the } \\
\text { predictor, and } S D_{\text {outcome }} \text { is the standard deviation of the outcome at Level } 1 \text { (e.g., Marsh et al., 2009, 2012; Morin et al., 2014). These ES indicators are comparable to Cohen's } \\
\text { d (1988) and reflect the difference in the outcome between two Level } 2 \text { units differing from one another by one standard deviation on the predictor. Level } 2 \text { contextual effects } \\
\text { (i.e., the effects of aggregated motivational constructs at the group level) were properly disaggregated from their level } 1 \text { counterpart by extracting the difference between the } \\
\text { Level } 2 \text { and Level } 1 \text { coefficients (Marsh et al., 2009, 2012; Morin et al., 2014). Contextual effects, } \beta \text { and ES were calculated using the multivariate delta method (e.g., Raykov } \\
\text { \& Marcoulides, 2004) implemented in Mplus via the MODEL CONSTRAINT function. }\end{array}$} \\
\hline
\end{tabular}




\section{SUPPLEMENTAL MATERIALS FOR:}

Uncovering relations between leadership perceptions and motivation under different organizational contexts: A multilevel cross-lagged analysis

\section{Authors' note:}

This supplemental material can be posted on the journal website and hot-linked to the manuscript. If the journal does not offer this possibility, these materials can alternatively be posted on one of our personal websites (we will adjust the in-text reference upon acceptance). We would also be happy to have some of these materials brought back into the main manuscript if you deem it useful.

\section{Preliminary Measurement Models}

Preliminary measurement models were estimated using the robust weighted least square estimator (WLSMV) available in Mplus 7.2 (Muthén \& Muthén, 2014), which has been found to outperform Maximum Likelihood (ML) estimation with Likert-type orderedcategorical items such as those used in the present study (e.g., Bandalos, 2014; Finney, \& DiStefano, 2006, 2013; Flora, \& Curran, 2004). These models were all estimated while taking into account individuals' nesting within managers with the design-based correction of standard errors available in Mplus 7.2 (Asparouhov, 2005; Muthén \& Muthén, 2014). To account for the fact that some respondents had some missing data within a specific time waves, or had failed to answer one of the time waves, all models were estimated based on the full information that was available, based on algorithms implemented in Mplus for WLSMV estimation (Asparouhov \& Muthén, 2010; Enders, 2010). Under missing at random assumptions (MAR), these procedures allow missing data to be conditional on all variables included in the model, which includes the variables themselves at preceding time points in the longitudinal panel design used here. In these models, a priori correlated uniquenesses between matching indicators of the factors utilized at the different time-points were included 
in longitudinal models to avoid converging on biased and inflated stability estimates (Jöreskog, 1979; Marsh, 2007). This inclusion reflects the fact that indicators' unique variance is known to emerge in part from shared sources of influences over time.

The fit of these models was evaluated using various indices as operationalized in Mplus 7.2 in conjunction with the WLSMV estimator (Hu \& Bentler, 1999; Yu, 2002): the WLSMV Chi-square statistic $\left(\chi^{2}\right)$, the Comparative Fit Index (CFI), the Tucker-Lewis Index (TLI), the Root Mean Square Error of Approximation (RMSEA), and its 90\% confidence interval. These fit indices are interpreted as in ML/MLR estimation, with values greater than .90 and .95 for both the CFI and TLI considered to be respectively indicative of adequate and excellent fit to the data. Values smaller than .08 or .06 for the RMSEA support respectively acceptable and excellent model fit. However, the estimated WLSMV chi-square values are not exact, but rather "estimated" as the closest integer necessary to obtain a correct p-value. Thus, in practice, only the p-value should be interpreted. This specificity of the WLSMV chisquare explains why sometimes the chi-square values and resulting CFI values can be nonmonotonic with model complexity. For the CFI, any increase when constraints are added should thus simply be interpreted as random, rather than as an improvement in fit. This specificity is especially important for the chi square difference tests, which cannot be computed by hand but needs to be conducted via Mplus' DIFFTEST function (MD $\Delta \chi^{2}$; Asparouhov, \& Muthén, 2006; Muthén, 2004). However, as the $\chi^{2}, \operatorname{MD} \Delta \chi^{2}$ tends to be oversensitive to sample size and to minor misspecifications, it is generally recommended to use additional indices to complement $\mathrm{MD} \Delta \chi^{2}$ when comparing nested models, such as in a sequence of measurement invariance test (Chen, 2007; Cheung, \& Rensvold, 2002). In these sequences, a CFI decline of .01 or less and a RMSEA increase of .015 or less between a model and the preceding model in the invariance hierarchy indicates that the measurement invariance hypothesis should not be rejected. 
However, there are still very few investigation of the efficacy of these fit indices and cut-off scores in the contest of WLSMV estimation (e.g. Yu, 2002) and, more importantly, to relatively complex models involving multiple factors and time points such as the models used in the present study (Marsh et al., 2005; Marsh, Hau, \& Wen, 2004). Thus, these cut-off scores should be considered as rough guidelines. Marsh et al. $(2004,2005)$ also suggest that inspection of fluctuations in fit indices that correct for parsimony (TLI and RMSEA) may be important given the large number of estimated parameters and the fact that these indices can improve when constraints are added to a model.

The first model of configural invariance simply assumed the same measurement model at both time points, without adding any invariance constraint to the model. In this model, the motivation instrument was modelled with an exploratory structural equation model specification (ESEM; Marsh, Morin, Parker \& Kaur, 2014; Morin, Marsh, \& Nagengast, 2013). This decision is based on recent results from Guay, Morin, Litalien, Valois and Vallerand (2014) which clearly demonstrated that human motivation, measured from the perspective of SDT, was best represented by way of an ESEM model allowing for the presence of small cross-loadings between items and conceptually-adjacent factors. Simulation studies have shown that ESEM generally tends to result in more adequate and less biased estimates of the correlations among conceptually adjacent constructs, and will still provide unbiased estimates of factor correlations when the underlying population model corresponds to the independent cluster assumption (i.e. no cross loadings) of confirmatory factor analyses - CFA (Asparouhov \& Muthén, 2009; Marsh, Lüdtke, Nagengast, Morin, \& Von Davier, 2013; Schmitt \& Sass, 2011). In the current study, the 3 global dimensions underlying the motivation instrument at each time point (amotivation, controlled motivation, and autonomous motivation) were estimated using target rotation, which allows for an a priori (i.e. confirmatory) specification of which items present their main loadings on which factors, 
while targeting all cross-loadings to be as close to zero as possible. Similarly, given the high levels of conceptual overlap previously reported among the TFL subscales (Antonakis et al., 2003) as well as our interest in the relations between motivation and a global factor of TFL, a bifactor-ESEM model (Reise, 2012) - in line with the previously reported hierarchical structure of this instrument (Avolio et al.,1999) but showing more flexibility in the estimation of the global factor using information from all items (e.g., Gignac, 2007; Morin, Arens, \& Marsh, 2015; Reise, 2012) - was used to estimate a global TFL factor while also controlling for the subscale-specific factors (only the global factor is used for hypothesis testing in this study). Finally, two additional factors were estimated at each time point to reflect TSL (active management by exception items) and PAL (passive management by exception and laissezfaire items).

Tests of measurement invariance across time points were conducted first in order to verify that the interpretations of the constructs had not changed over time points (e.g., Meredith, 1993; Millsap, 2011). These tests were performed in the following sequence (Meredith,1993; Millsap, 2011; Morin, Moullec, et al., 2011): (i) configural invariance (same measurement model), (ii) weak invariance (invariance of the factor loadings); (iii) strong invariance (invariance of the loadings and thresholds; with ordered categorical Likert items, thresholds replace the intercepts and reflect the points at which the scores change from one category to another); (iv) strict invariance (invariance of the loadings, thresholds and uniquenesses). Given our decision to rely on factor scores in the estimation of the main model, a critical assumption of our analyses was that the measurement model underlying the constructs would prove to be strictly invariant across time points (see Millsap, 2011).

The results from these models are reported in the top section of Table S1. The initial model of configural invariance, where the model was set to be the same at both measurement points without any additional added constraints, provided an excellent level of fit to the data 
according to the RMSEA (.018), and a fully adequate level of fit to the data according to the CFI (.946) and TLI (.940). Invariance constraints were progressively added to this model, and none of them resulted in a decrease in fit that came even close to the recommended guidelines for supporting measurement invariance.

As a final verification of the adequacy of the measurement models, we also tested their measurement invariance across the subgroups of employees from the organizations classified as being in crisis versus not in crisis. Due to the complexity of the measurement models estimated here, in conjunction with the relatively small sample size within some of the organizations, it was not possible to test measurement invariance across all six organizations/branches, or to test the measurement invariance of the longitudinal measurement models across types of organizations (these models all failed to converge). Still, we were able to test the measurement invariance of the Time 1 measurements models across types of organizations (in crisis versus not in crisis). The results from these tests are reported in the bottom section of Table S1 and supported the strict measurement invariance of the model across types of organizations. 
Table S1

Results from the Alternative Measurement Models

\begin{tabular}{|c|c|c|c|c|c|c|c|c|c|c|}
\hline Models & $\chi^{2}$ & $d l$ & RMSEA $(90 \% \mathrm{CI})$ & CFI & $T L I$ & $M D \Delta \chi^{2}$ & $\Delta d l$ & $\triangle R M S E A$ & $\triangle C F I$ & $\triangle T L I$ \\
\hline \multicolumn{11}{|c|}{ Longitudinal invariance of the first order measurement model } \\
\hline M1. Configural Invariance & $6995.036^{*}$ & 5427 & $.018(.017-.020)$ & .946 & .940 & - & - & - & - & - \\
\hline M2. Weak invariance (loadings) & $7129.189 *$ & 5582 & $.018(.017-.019)$ & .947 & .943 & $324.330 *$ & 155 & .000 & +.001 & +.003 \\
\hline M3. Strong invariance (thresholds) & $7361.202 *$ & 5772 & $.018(.017-.019)$ & .945 & .943 & $463.580^{*}$ & 190 & .000 & -.002 & .000 \\
\hline M4. Strict invariance (uniquenesses) & $7458.151 *$ & 5827 & $.018(.017-.019)$ & .944 & .942 & $215.076^{*}$ & 55 & .000 & -.001 & -.001 \\
\hline \multicolumn{11}{|c|}{ Multiple group invariance of the first order measurement model (Time 1) } \\
\hline M1. Configural Invariance & $3310.582 *$ & 2557 & $.029(.026-.031)$ & .967 & .961 & - & - & - & - & - \\
\hline M2. Weak invariance (loadings) & $3460.023 *$ & 2710 & $.028(.025-.030)$ & .967 & .964 & $277.613^{*}$ & 153 & -.001 & .000 & +.003 \\
\hline M3. Strong invariance (thresholds) & $3676.389 *$ & 2898 & $.027(.024-.030)$ & .966 & .965 & $326.665^{*}$ & 188 & -.001 & -.001 & +.001 \\
\hline M4. Strict invariance (uniquenesses) & $3738.202 *$ & 2953 & $.027(.024-.030)$ & .965 & .965 & $122.208 *$ & 55 & .000 & -.001 & .000 \\
\hline
\end{tabular}

Note. $\chi^{2}=$ WLSMV chi square; $d f=$ degrees of freedom; $R M S E A=$ Root mean square error of approximation; $90 \% C I=90 \%$ Confidence Interval for the RMSEA; $C F I=$ Comparative fit index; TLI = Tucker-Lewis index; $\Delta$ since previous model; MD $\Delta \chi^{2}:$ chi square difference test based on the Mplus DIFFTEST function for WLSMV estimation.

$* p<.01$ 


\section{References Used in the Supplements but not in the Main Manuscript}

Asparouhov, T. (2005). Sampling weights in latent variable modeling. Structural Equation Modeling, 12, 411-434.

Asparouhov, T., Muthén, B.O. (2006). Robust chi-square difference testing with mean and variance adjusted statistics. www.statmodel.com/examples/webnote.shtml\#web10

Asparouhov, T. \& Muthén, B.O. (2009). Exploratory structural equation modeling. Structural Equation Modeling, 16, 397-438. doi: 10.1080/10705510903008204

Asparouhov, T., Muthén, B.O. (2010). Weighted Least Square estimation with missing data. www.statmodel.com/download/GstrucMissingRevision.pdf

Bandalos, D. L. (2014). Relative performance of categorical diagonally weighted least squares and robust maximum likelihood estimation. Structural Equation Modeling, 21, 102-116. doi: $10.1080 / 10705511.2014 .859510$

Chen, F.F. (2007). Sensitivity of goodness of fit indexes to lack of measurement invariance. Structural Equation Modeling, 14, 464-504. doi: 10.1080/10705510701301834

Cheung, G. W., \& Rensvold, R.B. (2002). Evaluating goodness-of fit indexes for testing measurement invariance. Structural Equation Modeling, 9, 233-55. doi:10.1207/S15328007SEM0902_5

Guay, F., Morin, A.J.S, Litalien, D., Valois, P., \& Vallerand, R.J. (2014). Application of Exploratory Structural Equation Modeling to Evaluate the Academic Motivation Scale. The Journal of Experimental Education. Advanced online publication. DOI: $10.1080 / 00220973.2013 .876231$

Finney S. J., \& DiStefano, C. (2006). Non-normal and categorical data in structural equation modeling. In G. R. Hancock, \& R. O. Mueller (Eds.), Structural Equation Modeling: A Second Course (pp. 269-314). Greenwich, CO: IAP.

Finney S. J., \& DiStefano, C. (2013). Non-normal and categorical data in structural equation 
modeling. In G. R. Hancock, \& R. O. Mueller (Eds.), Structural Equation Modeling: A Second Course, second edition (pp. 439-492). Greenwich, CO: IAP.

Flora, D. B. \& Curran, P. J. (2004). An Empirical Evaluation of Alternative Methods of Estimation for Confirmatory Factor Analysis With Ordinal Data. Psychological Methods, 9, 466-491. doi: 10.1037/1082-989X.9.4.466

Gignac, G. E. (2007). Multi-factor modeling in individual differences research: Some recommendations and suggestions. Personality and Individual Differences, 42, 37-48. doi:10.1016/j.paid.2006.06.019

Hu, L. T., \& Bentler, P. M. (1999). Cutoff criteria for fit indexes in covariance structure analysis: Conventional criteria versus new alternatives. Structural Equation Modeling, 6, 1-55. doi: 10.1080/10705519909540118

Marsh, H. W. (2007). Application of confirmatory factor analysis and structural equation modeling in sport/exercise psychology. In G. Tenenbaum \& R. C. Eklund (Éds.), Handbook of on Sport Psychology ( $3^{\text {rd }}$ ed.). New York, NY: Wiley.

Marsh, H. W., Hau, K.-T., \& Grayson, D. (2005). Goodness of fit evaluation in structural equation modeling. In A. Maydeu-Olivares \& J. McArdle (Eds.), Psychometrics. A Festschrift to Roderick P. McDonald (pp. 275-340). Hillsdale, NJ: Erlbaum.

Marsh, H. W., Hau, K.-T., \& Wen, Z. (2004). In search of golden rules: Comment on hypothesis testing approaches to setting cutoff values for fit indexes and dangers in over-generalizing Hu \& Bentler's (1999) findings. Structural Equation Modeling, 11, 320-341. doi: 10.1207/s15328007sem1103_2

Marsh, H.W., Lüdtke, O., Nagengast, B., Morin, A.J.S., \& Von Davier, M. (2013). Why item parcels are (almost) never appropriate: Two wrongs do not make a rightCamouflaging misspecification with item parcels in CFA models. Psychological Methods, 18, 257-284. doi: 10.1037/a0032773 
Marsh, H.W., Morin, A.J.S., Parker, P.D., \& Kaur, G. (2014). Exploratory structural equation modelling: An integration of the best features of exploratory and confirmatory factor analyses. Annual Review of Clinical Psychology, 10, 85-110. doi: 10.1146/annurevclinpsy-032813-153700

Morin, A. J. S., Marsh, H. W., \& Nagengast, B. (2013). Exploratory structural equation modeling. In Hancock, G. R., \& Mueller, R. O. (Eds.). Structural equation modeling: A second course (2nd ed., pp. 395-436). Charlotte, NC: Information Age Publishing, Inc.

Morin, A.J.S., Arens, A.K., \& Marsh, H.W. (2016, In Press). A Bifactor exploratory structural equation modeling framework for the identification of distinct sources of construct-relevant psychometric multidimensionality. Structural Equation Modeling.

Morin A.J.S., Moullec G., Maïano C., Layet, L., Just, J.-L., \& Ninot G. (2011). Psychometric properties of the Center for Epidemiologic Studies Depression Scale (CES-D) in French Clinical and Non-Clinical Adults. Epidemiology and Public Health, 59, 327-340. doi: 10.1016/j.respe.2011.03.061

Muthén, B. O. (2004). Mplus Technical Appendices. http://www.statmodel.com/techappen.shtml.

Reise, S.P. (2012). The rediscovery of bifactor measurement models. Multivariate Behavioral Research, 47, 667-696. doi: 10.1080/00273171.2012.715555

Schmitt, T.A., \& Sass, D.A. (2011). Rotation criteria and hypothesis testing for exploratory factor analysis: implications for factor pattern loadings and interfactor correlations. Educational \& Psychological Measurement, 71, 95-113. doi: $10.1177 / 0013164410387348$

Yu, C. Y. (2002). Evaluating cutoff criteria of model fit indices for latent variable models with binary and continuous outcomes. Los Angeles, CA: University of California. 